Article

\title{
Towards Iron(II) Complexes with Octahedral Geometry: Synthesis, Structure and Photophysical Properties
}

\author{
Mohamed Darari ${ }^{1}$, Antonio Francés-Monerris ${ }^{2,3}{ }^{\oplus}$, Bogdan Marekha ${ }^{4}{ }^{\oplus}$, Abdelatif Doudouh $^{5}$, \\ Emmanuel Wenger ${ }^{5}$, Antonio Monari ${ }^{2}$ (D), Stefan Haacke ${ }^{6}$ and Philippe C. Gros ${ }^{1, *(D)}$ \\ 1 Université de Lorraine, CNRS, L2CM, F-54000 Nancy, France; mohamed.darari@univ-lorraine.fr \\ 2 Université de Lorraine, CNRS, LPCT, F-54000 Nancy, France; antonio.frances@univ-lorraine.fr (A.F.-M.); \\ Antonio.Monari@univ-lorraine.fr (A.M.) \\ 3 Departament de Química Física, Universitat de València, 46100 Burjassot, Spain \\ 4 Max-Planck-Institute for Medical Research, 69120 Heidelberg, Germany; bogdan.a.marekha@gmail.com \\ 5 Université de Lorraine, CNRS, CRM2, F-54000 Nancy, France; abdelatif.doudouh@univ-lorraine.fr (A.D.); \\ emmanuel.wenger@univ-lorraine.fr (E.W.) \\ 6 Université de Strasbourg, CNRS, IPCMS, F-67034 Strasbourg, France; stefan.haacke@ipcms.unistra.fr \\ * Correspondence: philippe.gros@univ-lorraine.fr
}

Received: 30 October 2020; Accepted: 14 December 2020; Published: 17 December 2020

\begin{abstract}
The control of ligand-field splitting in iron (II) complexes is critical to slow down the metal-to-ligand charge transfer (MLCT)-excited states deactivation pathways. The gap between the metal-centered states is maximal when the coordination sphere of the complex approaches an ideal octahedral geometry. Two new iron(II) complexes (C1 and C2), prepared from pyridylNHC and pyridylquinoline type ligands, respectively, have a near-perfect octahedral coordination of the metal. The photophysics of the complexes have been further investigated by means of ultrafast spectroscopy and TD-DFT modeling. For C1, it is shown that-despite the geometrical improvement-the excited state deactivation is faster than for the parent pseudo-octahedral $\mathrm{C} 0$ complex. This unexpected result is due to the increased ligand flexibility in $\mathbf{C} \mathbf{1}$ that lowers the energetic barrier for the relaxation of ${ }^{3} \mathrm{MLCT}$ into the ${ }^{3} \mathrm{MC}$ state. For $\mathrm{C} 2$, the effect of the increased ligand field is not strong enough to close the prominent deactivation channel into the metal-centered quintet state, as for other Fe-polypyridine complexes.
\end{abstract}

Keywords: iron (II) complexes; octahedral geometry; excited states dynamics; density functional theory; time-resolved spectroscopy

\section{Introduction}

Ligand-field splitting is an important parameter with a deep impact on the photophysics of transition metal-based complexes. Indeed, its fine tuning is crucial to populate long-lived metal-to-ligand charge transfer (MLCT) states that are required for triggering light induced functions such as photochemically induced electron transfer [1-5]. The control of the ligand-field splitting is particularly challenging in iron (II) polyimine complexes where the MLCT states, first populated upon photo excitation, undergo an ultrafast deactivation into the low-lying metal-centered (MC) states, thus leading to the loss of the suitable photophysical properties [6,7].

$\mathrm{N}$-heterocyclic carbenes (NHC) ligands, ideally combining a strong $\sigma$-donating and a weak-to-moderate $\pi$-accepting character, have been reported to destabilize the MC states over the MLCT manifold, thus impressively slowing down the deactivation pathways. In this context, tridentate pyridyldicarbene ligands with appropriate modifications of both the NHC side and the central azine 
have been reported by us and other groups as leading to remarkable ${ }^{3}$ MLCT lifetimes in the 9-32 ps range for the corresponding iron (II) complexes [4,8-14]. Other ligands giving rise to more rigid complexes [15] or different coordination architectures [16] have achieved impressive MLCT lifetimes beyond hundreds of picoseconds. A comprehensive review of the rapid advances in this area was recently published [17].

The ligand-field splitting can also be enhanced by reducing the angular strain around the metal center [18-22], i.e., when the coordination geometry is as close as possible to a perfect octahedron, as seen for example in some heavy metal complexes. For example, the angularly strained $\left[\mathrm{Ru}(\mathrm{tpy})_{2}\right]^{2+}$ complex (tpy $=2,2^{\prime}: 6^{\prime}, 2^{\prime \prime}$-terpyridine) experiences an ultrafast population of MC states [23], while the weakly distorted bidentate homologue $\left[\mathrm{Ru}(\mathrm{bpy})_{3}\right]^{2+}\left(\mathrm{bpy}=2,2^{\prime}\right.$-bipyridine) [24] is strongly luminescent at room temperature with excited-state lifetimes up to $1 \mathrm{~ms}$ since the access to deactivating MC states is hampered [25].

In the case of Ru-based compounds, the angular strain has been minimized by switching from tridentate to bidentate ligands. We have recently shown that the use of a bidentate pyridylNHC ligands also improved notably the excited state lifetimes of iron complexes compared to their tridentate analogues [11].

However, in contrast to tridentate ligands, the dissymmetrical bidentate ligands generally form mixtures of fac and mer isomers, which can be problematic when a vectorial electron transfer is required [26]. In addition, it has also been shown that the fac and mer isomerism may lead to unexpected photophysical consequences $[11,13,14]$. Thus, the possibility of achieving tridentate iron complexes with reduced angular strain still appears extremely attractive for the design of photoelectrochemical active agents. While some elegant approaches to increase the ligand field using tridentate ligands have been developed [18,27-29] there is a lack of such advances for iron (II) complexes, and the benefit of an improved octahedral coordination on the excited state relaxation dynamics has only be explored for an Fe(II) complex with 2,6-bis(2-carboxypyridyl)pyridine ligands [30]. Here, it was shown that the higher ligand field splitting destabilizes the ${ }^{5} \mathrm{MC}$, leading to a faster deactivation of this quintet state.

Herein we report the synthesis, structural characterization and photophysics of the novel homoleptic complexes C1 and C2 (Figure 1) based on relevant tridentate ligands selected for their ability to create an almost perfect octahedral geometry of the coordination sphere. In particular, we focus on the dqp (2,6-diquinolylpyridine) ligand, which has been reported to give a close to perfect octahedral complexes having a great impact on the MLCT lifetimes that reached the microsecond scale for the homoleptic Ru(dqp) ${ }_{2}{ }^{2+}$ complex (C2) [18]. A second ligand structure achieved by introducing methylene spacers on the 2,6-Bis(1-methylimidazolylidene) pyridine ligand has been used to make C1. It shall be noted that the 2,6-Bis(1-methylimidazolylidene) pyridine has been previously reported to give $\mathbf{C} 0$, a complex with a distorted octahedral $\mathrm{Fe}^{2+}$ coordination exhibiting MLCT lifetimes of 9 ps [8].

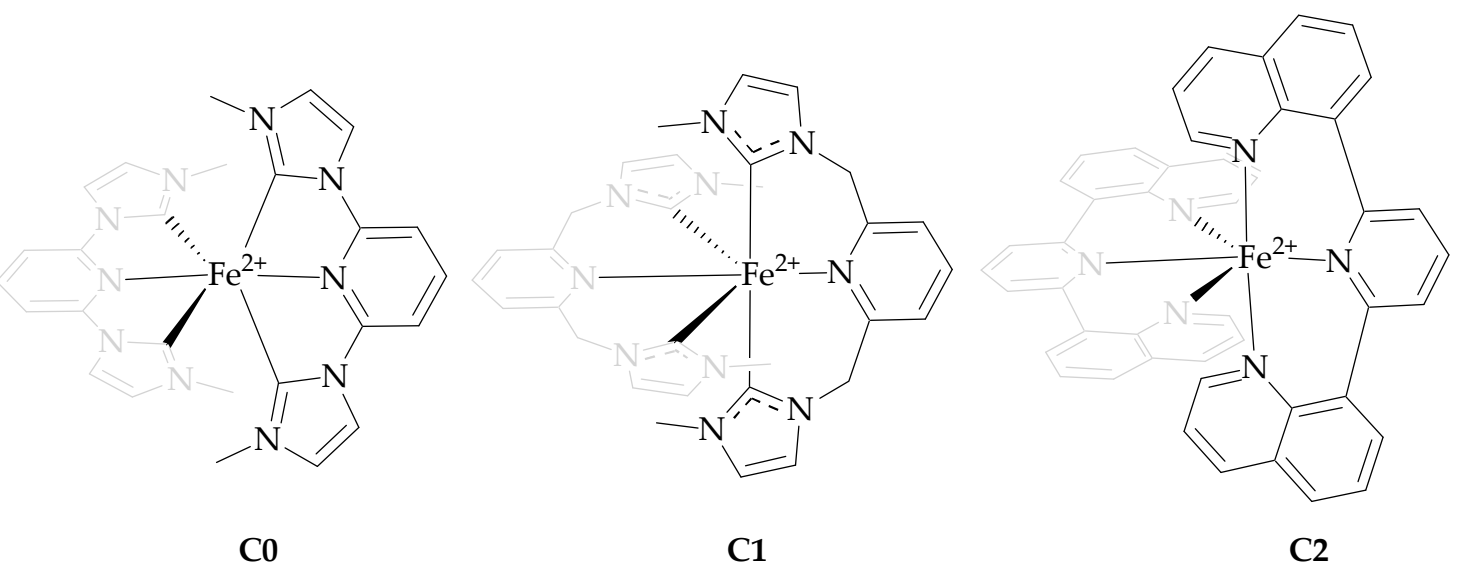

Figure 1. Complexes studied in this work. In all cases, counter ion is $\mathrm{PF}_{6}{ }^{-}$. 
By such modifications, we investigated the effects induced by the optimal coordination geometry on the photophysical properties of these new iron complexes aiming to extend the excited-state lifetimes analogously to the reported case of ruthenium.

\section{Results}

\subsection{Synthesis and Characterization}

\subsubsection{Synthesis of Ligands and Complexes}

The access to $\mathbf{C} \mathbf{1}$ required the synthesis of the pyridylimidazolium salt precursor L1. It was obtained in 80\% yield from 2,6-bis(bromomethyl)pyridine and 1-methylimidazole according to the literature [31]. L1 was subsequently involved in the coordination process by a first reaction with $\mathrm{FeBr}_{2}$ followed by the addition of $t \mathrm{BuOK}$ to generate the carbene (Scheme 1 ). When performed at room temperature, the reaction led to degradation of L1. However, the coordination was successfully made by decreasing the temperature to $0^{\circ} \mathrm{C}$ affording $\mathrm{C} 1$ in $19 \%$ yield. The low coordination yield obtained is in agreement with those obtained previously with $\mathrm{Fe}(\mathrm{II}) \mathrm{NHC}$ ligands $[4,9,13]$.

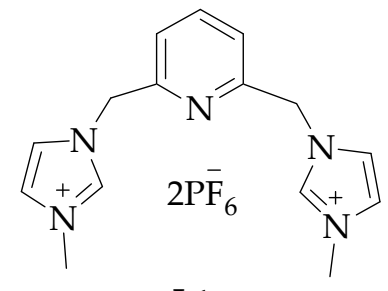

L1
1) $\mathrm{FeBr}_{2}(0.5 \mathrm{eq})$ anhydrous DMF

2) $\mathrm{tBuOK}$ à $0^{\circ} \mathrm{C}$, then r.t., $16 \mathrm{~h}$

3) $\mathrm{KPF}_{6}$

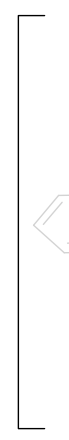

Scheme 1. Synthesis of complex C1.

The diquinolinylpyridine (dqp) ligand required for the synthesis of $\mathbf{C} 2$ has been obtained in $65 \%$ yield employing a Suzuki cross-coupling between 8-quinoline boronic acid and 2,6-dibromopyridine according to a reported procedure [18]. The coordination of this ligand with iron was first attempted by mixing $\mathrm{FeBr}_{2}$ and dqp, where regardless of the temperature and solvent used, no complex formation was detected. Switching to a microwave irradiation $(60 \mathrm{~W})$ in refluxing DMF for $4 \mathrm{~h}$ gave the expected complex C2 in 30\% yield (Scheme 2). Another iron precursor has been tested by using ammonium iron(II) sulfate hexahydrate $\left[\mathrm{Fe}\left(\mathrm{NH}_{4}\right)_{2}\left(\mathrm{SO}_{4}\right)_{2}\right]_{6} \mathrm{H}_{2} \mathrm{O}$. Overnight reaction at room temperature in acetonitrile gave $\mathbf{C} 2$ also in $30 \%$ yield.

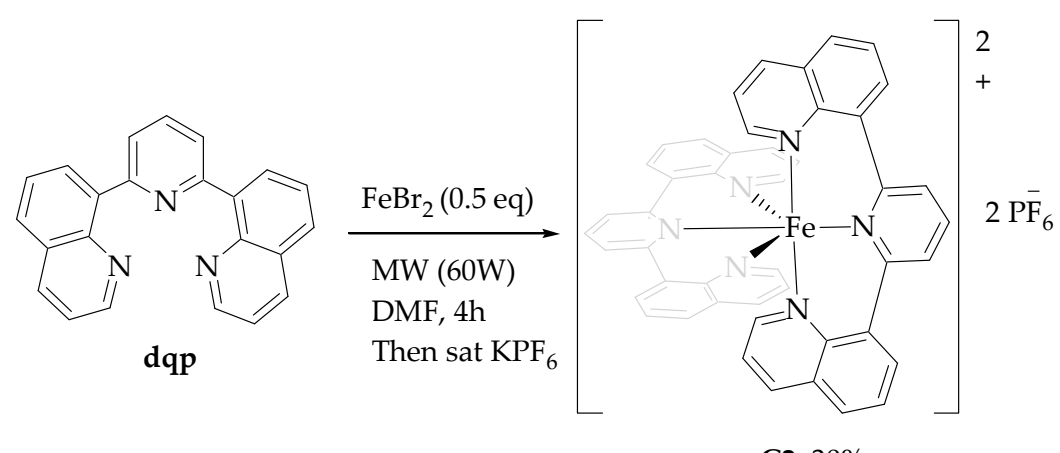

C2, 30\%

Scheme 2. Synthesis of complex C2. 


\subsubsection{X-Ray Structures}

Single crystals of the two complexes suitable for X-ray diffraction analysis were obtained from slow evaporation of acetonitrile solution. X-ray crystal structures of the complexes C1 and C2 are shown in Figures 1 and 2, and selected bond lengths and bond angles are given in Tables 1 and 2.
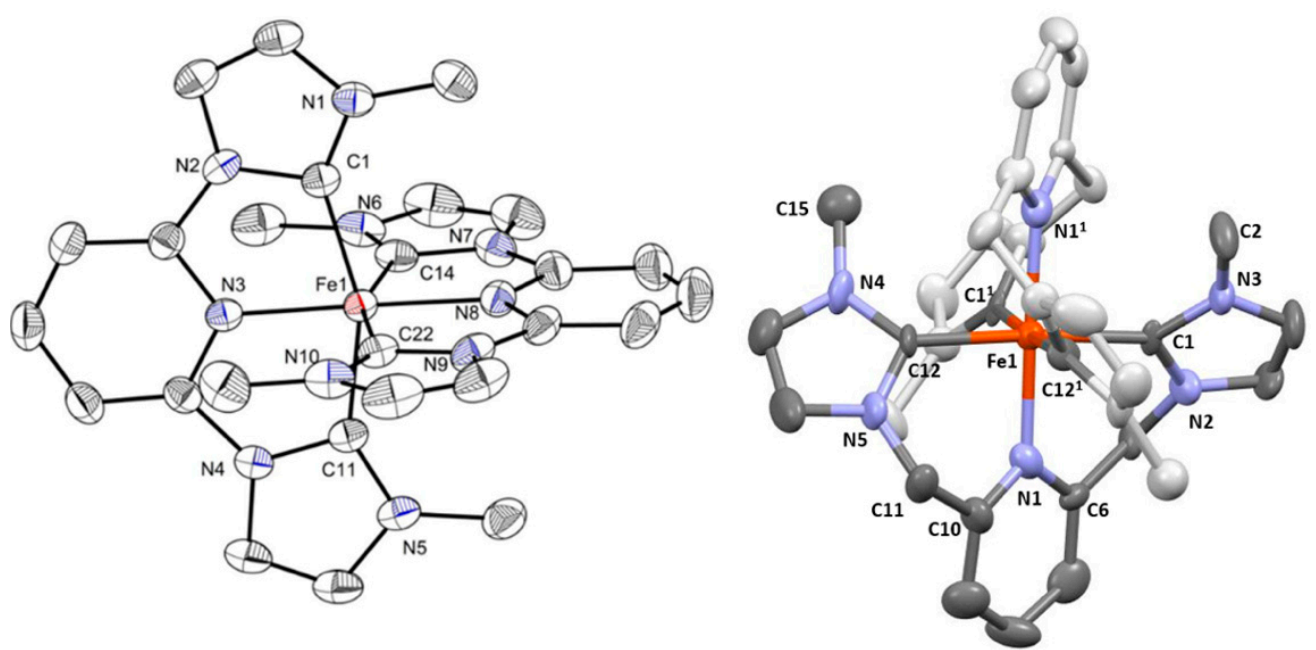

Figure 2. Crystallographic structures of $\mathbf{C 0}$ (left) [8] and $\mathbf{C 1}$ (right). Hydrogen bonds and $\mathrm{PF}_{6}$ molecules are omitted for clarity. Thermal ellipsoids are set to $50 \%$ probability level.

Table 1. Bond lengths and coordination angles of $\mathbf{C} 0$ and $\mathbf{C 1 .}$

\begin{tabular}{|c|c|c|c|c|c|c|c|}
\hline \multicolumn{4}{|c|}{ Bond Length (Å) } & \multicolumn{4}{|c|}{ Angles $\left({ }^{\circ}\right)$} \\
\hline \multicolumn{2}{|c|}{$\mathrm{CO}$} & \multicolumn{2}{|c|}{$\mathrm{C1}$} & \multicolumn{2}{|l|}{$\mathrm{CO}$} & \multicolumn{2}{|l|}{$\mathrm{C} 1$} \\
\hline Fe1-N3 & $1.919(3)$ & Fe1-N1 & $2.035(11)$ & C1-Fe1-N3 & $79.5(1)$ & C1-Fe1-N1 & $87.7(5)$ \\
\hline $\mathrm{Fe}-\mathrm{N} 8$ & $1.930(3)$ & Fe1-N1' & $2.035(11)$ & C11-Fe1-N3 & $79.2(1)$ & C12-Fe1-N1 & $88.5(4)$ \\
\hline Fe1-C11 & $1.965(3)$ & Fe1-C12 & $1.981(11)$ & C1-Fe1-C11 & $158.0(2)$ & C12-Fe1-C1 & $176.1(5)$ \\
\hline Fe1-C14 & $1.965(3)$ & Fe1-C1' & $1.981(10)$ & C14-Fe1-N8 & $79.0(1)$ & $\mathrm{C} 1^{\prime}-\mathrm{Fe} 1-\mathrm{N} 1^{\prime}$ & $87.7(5)$ \\
\hline Fe1-C1 & $1.966(3)$ & Fe1-C1 & 1.981(10) & C22-Fe1-N8 & $79.0(1)$ & $\mathrm{C} 12^{\prime}-\mathrm{Fe} 1-\mathrm{N} 1^{\prime}$ & $88.5(5)$ \\
\hline $\mathrm{Fe}-\mathrm{C} 22$ & $1.970(3)$ & Fe1-C12' & 1.981(11) & $\mathrm{C} 14-\mathrm{Fe} 1-\mathrm{C} 22$ & $158.0(2)$ & $\mathrm{C} 1^{\prime}-\mathrm{Fe} 1-\mathrm{C} 12^{\prime}$ & $176.1(5)$ \\
\hline
\end{tabular}

Table 2. Bond lengths and coordination angles of $\mathbf{C}$.

\begin{tabular}{|c|c|c|}
\hline \multicolumn{2}{|c|}{ Bond Length (Å) } & \multirow{2}{*}{\begin{tabular}{c}
\multicolumn{2}{c}{ Angles $\left(^{\circ}\right)$} \\
N2-Fe1-N3 90.36(9)
\end{tabular}} \\
\hline Fe1-N2 & $1.961(2)$ & \\
\hline Fe1-N2' & $1.957(2)$ & N3'-Fe1-N1 90.88(8) \\
\hline Fe1-N1 & $1.997(2)$ & N3-Fe1-N1 177.58(8) \\
\hline Fe1-N1' & $1.997(2)$ & N2'-Fe1-N1'90.15(9) \\
\hline Fe1-N3 & $1.986(2)$ & $\mathrm{N} 2^{\prime}-\mathrm{Fe} 1-\mathrm{N} 3^{\prime} 90.48(9)$ \\
\hline Fe1-N3' & $1.995(2)$ & $\mathrm{N}^{\prime}-\mathrm{Fe} 1-\mathrm{N} 1179.21(9)$ \\
\hline
\end{tabular}

In contrast to its parent complex $\mathrm{C} 0$, which has a bite angle of $158^{\circ}$ [8], the geometry around the central iron atom in $\mathrm{C} 1$ is very close to fully octahedral as shown by the increased bite angles $\left(176.1^{\circ}\right)$ afforded by the flexibility provided by the methylene extension. The Fe-Pyridine bonds are longer than those of $C 0$ (2.035 vs. $1.930 \AA$ ), which agrees with the widening of the coordination sphere in $C 1$.

Like its ruthenium homologue [18], the crystallographic angles confirm the optimization of the octahedral symmetric coordination sphere of C2 (Figure 3). Indeed, ideal coordination angles close to $90^{\circ}$ on average have been obtained (Table 2), while maintaining bite angles close to $180^{\circ}$. The $\mathrm{Fe}-\mathrm{N}$ (quinoline) bonds are slightly longer than the two $\mathrm{Fe}-\mathrm{N}$ (pyridine) bonds due to the better 
charge delocalization in quinoline, increasing the electronic density and the amount of antibonding interactions with the iron d orbitals.

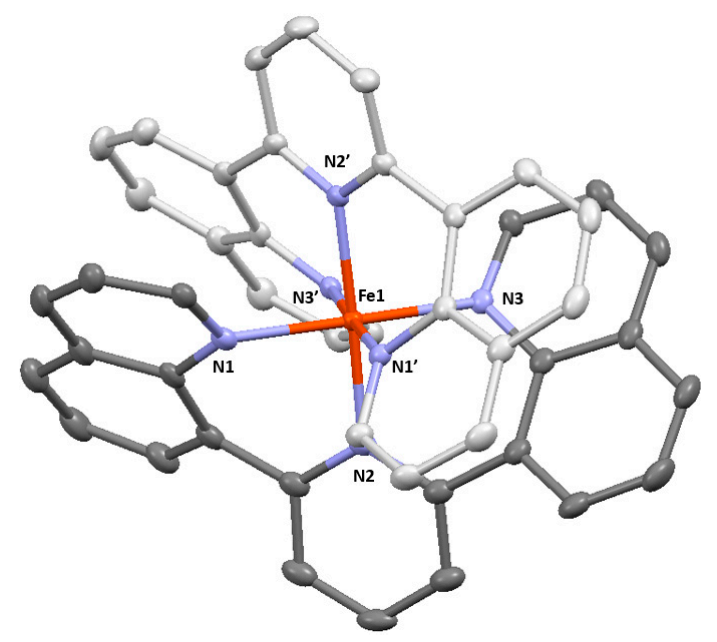

Figure 3. Crystallographic structure of $\mathbf{C}$. Hydrogen bonds and $\mathrm{PF}_{6}$ molecules are omitted for clarity. Thermal ellipsoids are set to $50 \%$ probability level.

\subsubsection{Electronic and Electrochemical Properties}

The electronic and optical properties of both complexes were investigated by means of steady-state UV-vis spectroscopy (Figure 4) and cyclic voltammetry (Table 3).

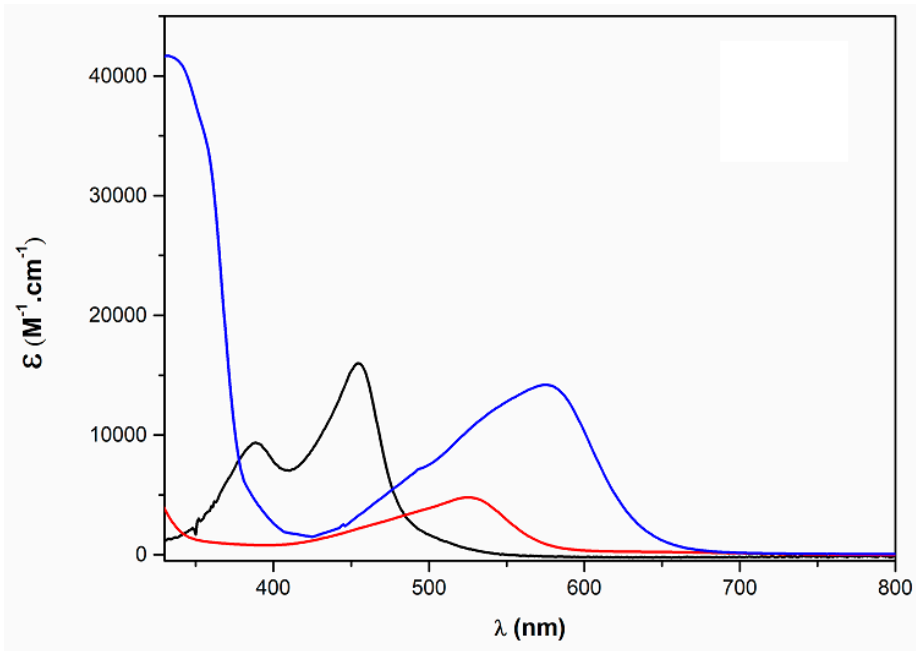

Figure 4. UV-Vis spectra of C0 (black), C1 (red) and C2 (blue) in acetonitrile.

Table 3. Photophysical and electrochemical properties of $\mathbf{C} 0, \mathbf{C} 1$ and $\mathbf{C} 2$.

\begin{tabular}{|c|c|c|c|c|}
\hline Complex & $\begin{array}{c}\lambda \text { abs-Max }^{\mathrm{a}}(\mathrm{nm}) \\
\varepsilon\left(\mathbf{M}^{-1} \cdot \mathrm{cm}^{-1}\right)\end{array}$ & $\begin{array}{c}\mathrm{E}_{\mathrm{ox}} \\
\left(\mathrm{Fe}^{\mathrm{III}} / \mathrm{Fe}^{\mathrm{II}}\right)^{\mathrm{b}}(\mathrm{V} / \mathrm{SCE})\end{array}$ & $\begin{array}{c}E_{\text {red1 }} \\
\text { (V/SCE) }\end{array}$ & $\Delta \mathrm{E}^{\mathrm{c}}(\mathrm{eV})$ \\
\hline $\mathrm{CO}$ & $\begin{array}{l}393(9000) \\
460(15,900)\end{array}$ & 0.71 (rev) & $\begin{array}{l}-2.00 \\
\text { (irrev) }\end{array}$ & 2.75 \\
\hline C1 & $525(4800)$ & 0.31 (rev) & $\begin{array}{l}-2.05 \\
\text { (irrev) }\end{array}$ & 2.36 \\
\hline $\mathrm{C} 2$ & $575(14,200)$ & 0.96 (rev) & $\begin{array}{l}-1.35 \\
(\mathrm{rev})\end{array}$ & 2.31 \\
\hline
\end{tabular}

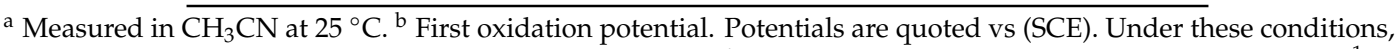
$\mathrm{E}_{1 / 2}(\mathrm{Fc}+\mathrm{Fc})=0.39 \mathrm{~V} / \mathrm{SCE}$. Recorded in $\mathrm{CH}_{3} \mathrm{CN}$ using $\mathrm{Bu}_{4} \mathrm{~N}^{+}, \mathrm{PF}_{6}{ }^{-}(0.1 \mathrm{M})$ as supporting electrolyte at $100 \mathrm{mV} . \mathrm{s}^{-1}$. $^{\mathrm{c}}$ Electrochemical band gap $\left(\Delta \mathrm{E}=\mathrm{E}_{\mathrm{ox}}-\mathrm{E}_{\mathrm{red} 1}\right)$. 
The UV-Vis spectra of both complexes present two types of absorption bands. Very intense bands are in the UV range $(<350 \mathrm{~nm})$ and are ascribed to bright $\pi-\pi^{*}$ transitions localized on the ligands. For each complex, one distinct, broader, and less intense band is found at longer wavelengths in the visible range. The absorption spectrum of $\mathbf{C} 2$ presents a better spectral coverage, its absorption band at $575 \mathrm{~nm}$ $\left(14,200 \mathrm{M}^{-1} \mathrm{~cm}^{-1}\right)$ is notably red-shifted by $50 \mathrm{~nm}$ as compared to the maximum absorption band of $\mathbf{C 1}$, which peaks at $525 \mathrm{~nm}\left(4800 \mathrm{M}^{-1} \mathrm{~cm}^{-1}\right)$. This bathochromic shift can be attributed to the combination of the geometric stabilization and the electron-withdrawing effects of quinolines stabilizing the MLCT states. One can note that for $\mathbf{C} \mathbf{1}$, the characteristic absorption band of the Fe-carbene transitions is no longer visible or resolved as it is the case in its parent complex C0, there with a maximum at $393 \mathrm{~nm}$. This transition is most probably hidden in the broad MLCT absorption band in the 420-500 nm range. The decrease in the absorption capacity observed in $\mathbf{C} \mathbf{1}$ could be related to the small barrier between singlet and triplet MLCT states (see Figure 8) producing an increased triplet character.

The redox properties of both complexes were measured by cyclic voltammetry with SCE as standard electrode and compared in Table 3.

For C2, as compared to $\mathrm{C}$, electrochemical measurements show an increase of the $\mathrm{Fe}^{\mathrm{II}} / \mathrm{Fe}^{\mathrm{III}}$ oxidation potential $(0.96 \mathrm{~V}$ vs. $0.71 \mathrm{~V})$ due to the $\pi$-acceptor effect of quinolines. The reduction potential is also increased $(-1.35 \mathrm{~V}$ vs. $-2.00 \mathrm{~V})$, which could be ascribed in a first approximation to a lower LUMO energy level due to a greater stabilization through extended $\pi$-conjugation in the bqp ligand compared to the NHC ligand in $\mathbf{C 0}$. The lower electrochemical gap is in good agreement with the bathochromic effect observed in the UV-Vis spectra.

For $\mathrm{C1}$, a strong decrease of the $\mathrm{Fe} / \mathrm{Fe}$ III oxidation potential is observed compared to its parent complex $\mathbf{C 0}(0.31 \mathrm{~V}$ vs. $0.71 \mathrm{~V})$ which is indicative of the marked increase of the $\sigma$-donating character of the carbene moieties which are no more conjugated with the pyridine as in $\mathbf{C 0}$. However, $\mathbf{C} \mathbf{1}$ exhibits an irreversible monoelectronic transfer at $-2.05 \mathrm{~V}$ occurring at about the same potential as $\mathrm{C} 0$ indicating for these two complexes higher energy levels of the $\pi^{*}$ orbitals than for $\mathbf{C} 2$.

\subsection{Excited State Relaxation Dynamics}

The effects of the ligand geometry of the coordination sphere on the excited state lifetimes was investigated for compounds $\mathbf{C} 1$ and $\mathbf{C} 2$ by femtosecond transient absorption spectroscopy (fs-TAS) and compared to $\mathbf{C} \mathbf{0}$, as reference [8].

\subsubsection{Fs-TAS of $\mathrm{C} 1$}

C1 dissolved in acetonitrile $(\mathrm{ACN})$ was excited with $\approx 50 \mathrm{fs}$ pump pulses at $495 \mathrm{~nm}$, and the pump-induced absorbance changes $\Delta \mathrm{A}$, with no more than $10 \%$ ground state depletion, were probed by a white-light continuum generated in a 2-mm thin $\mathrm{CaF}_{2}$ plate in the range of 320-640 nm. Figure 5 displays the time-dependent $\triangle \mathrm{A}$, and the sign-inverted ground state absorption spectrum (GSA) for comparison. The TAS data show at all times a negative ground state bleach (GSB) in the range of 410-540 $\mathrm{nm}$ at early delays, with a peak at $507 \mathrm{~nm}$. Positive $\Delta \mathrm{A}$ due to excited state absorption (ESA) is identified in the blue part of the GSB, below $400 \mathrm{~nm}$, and in the red, above 520-540 nm. Note that both ESA bands have significant overlap with the GSB, since the latter is visible only in a limited range of the GSA spectrum, due to the larger absorption cross section of ESA in the ranges where $\Delta \mathrm{A}>0$. Clear spectral evolution occurs on a sub-300 fs time scale in the blue ESA band, shifting the ESA-GSB crossover around $400 \mathrm{~nm}$ by $20 \mathrm{~nm}$, and in the red ESA during a longer time period, i.e., the first 10 ps (25 nm red-shift). This indicates that different species contribute to the ESA, populated along a relaxation scheme we will identify in what follows. 


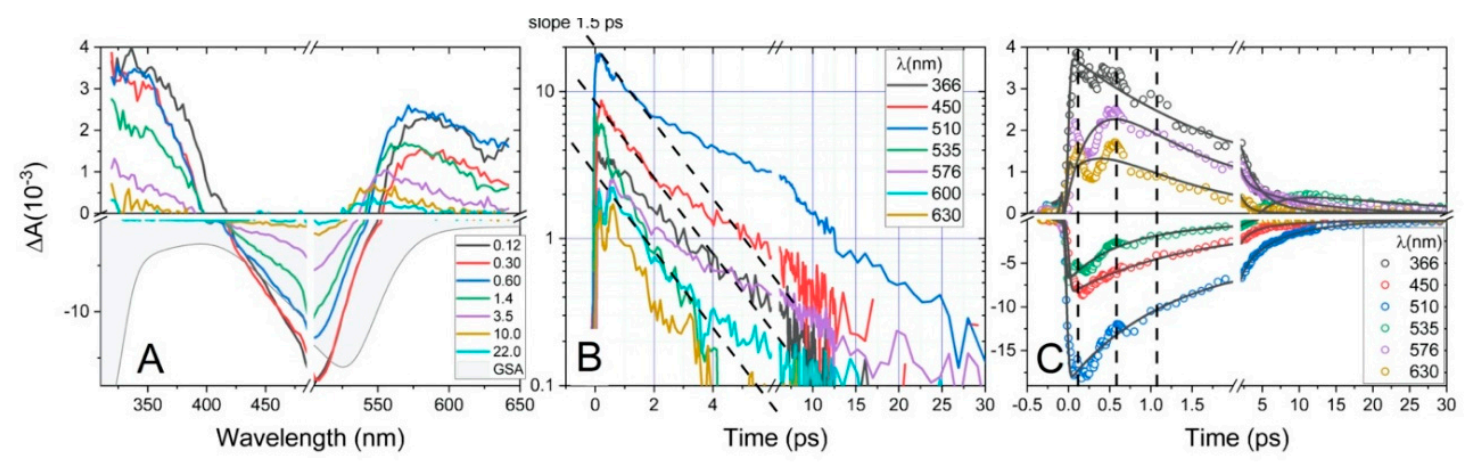

Figure 5. Femtosecond TAS data of $\mathbf{C} 1$ in acetonitrile (ACN) after excitation at $495 \mathrm{~nm}$. (A): Time-dependent spectra for delays in ps, as indicated in the legend. Ground state absorption (GSA) is the sign-inverted ground state absorption spectrum. Note the different scales for the positive and negative parts of $\Delta \mathrm{A}$. The $480-505 \mathrm{~nm}$ range is disregarded due to excessive pump light scattering. (B): Decay transients at selected wavelengths (cf. legend) plotted on a semi-log scale with a break in the time axis at 6 ps. GSB traces are sign inverted. Dashed lines are guides-to-the-eye with a 1.5 ps decay slope, highlighting that the initial fast decay of the signals is in that time range. When the signal-to-noise is large enough, an additional 10-15 ps decay emerges. (C): Decay transients at selected wavelengths (cf. legend) plotted on a linear scale with a break in the time axis at $2.0 \mathrm{ps}$. Dashed vertical lines mark the occurrence of oscillatory maxima in the excited state absorption (ESA) with a period of $\approx 0.5$ ps. Solid black lines are the best fits to the data, without accounting for the oscillatory part. Note the different scales for the positive and negative parts of $\Delta \mathrm{A}$. Transients are averaged over $\pm 5 \mathrm{~nm}$.

Another interesting observation is related to periodic modulations in the ESA amplitude. Figure 5C highlights these for the blue and red ESA $(366,576,630 \mathrm{~nm})$, and for the longer wavelength part of the GSB (510 and $535 \mathrm{~nm}$ ), but not for $450 \mathrm{~nm}$. The oscillation period is difficult to determine precisely as damping is strong, but it can be determined to be of the order of $0.5 \mathrm{ps}$. Maxima of the oscillatory features in ESA correspond to minima at the wavelengths of negative $\triangle \mathrm{A}$. Keeping in mind that the latter is a result of overlapping ESA and GSB, one can conclude, in particular for $\lambda>450 \mathrm{~nm}$, that the modulations are in the ESA signal only. In other words, the excited state transition dipole moment is modulated by a strongly damped but coherent vibrational motion with a frequency of $\approx 60 \mathrm{~cm}^{-1}$. See SI for a more quantitative analysis, and higher frequency ground state oscillations.

Regarding the excited state lifetimes and relaxation scenario, Figure 5B plots kinetic traces on a semi-log scale, so as to highlight the components of exponential decay. Dashed black lines with a slope of 1.5 ps overlay with the initial portion of most of the kinetic traces. When the signal-to-noise ratio is high enough, an additional slower component, 10-15 ps, is observed (450, 510, 576 and $600 \mathrm{~nm}$ ). All kinetic traces can be well fitted by a sum of three exponentials with wavelength-dependent amplitudes and decay constants, $\sum_{i=1}^{3} A_{i}(\lambda) e^{-t / \tau_{i}(\lambda)}$, convoluted with a Gaussian instrument response function (width $50 \mathrm{fs}$ ). The results of single wavelength fits are displayed as solid black lines in Figure 5C. They reveal a rise time, in the $\approx 0.3 \mathrm{ps}$ range, for the red ESA part (576 and $630 \mathrm{~nm}$ ). Table $S 16$ in the Supplementary Materials gives the fit parameters for individual wavelengths. The fastest ESA decay and GSB recovery time is $\tau_{2}=0.8-1.5 \mathrm{ps}$, and the second decay is found by $\tau_{3}=7-17 \mathrm{ps}$, with an overall 8-10 times smaller amplitude than $\tau_{2}$.

Global analysis, i.e., fits of the full data set, but with wavelength-independent lifetimes, $\sum_{i=1}^{3} A_{i}(\lambda) e^{-t / \tau_{i}}$, were carried out, using OPTIMUS [32] and the results displayed as decay-associated difference spectra (DADS, $A_{i}(\lambda)$ ) in Figure 6A. The oscillatory components are neglected in these fits, but they represent the qualitative trends of Figure 5. The validity of such global fitting is assessed in detail in the Supplementary Materials (cf. Figure S7). First, the negative amplitude of the 0.3-ps DADS in the blue and red ESA regions reflect the observed rise. Likewise, its positive amplitude in the $380-450 \mathrm{~nm}$ range is consistent with the slightly rising GSB signal in this time and wavelength ranges (Figure 5C). Second, the double exponential decay character of both ESA and GSB is reliably 
reproduced in the DADS of $\tau_{2}=1.3 \mathrm{ps}$ and $\tau_{2}=7.3 \mathrm{ps}$. We find that the amplitude of $\tau_{2}$ is approx. 10 times larger than the one of $\tau_{3}$ in the blue ESA band and above $580 \mathrm{~nm}$. However, since the ESA amplitudes depend on the respective cross sections and overlap with the GSA, it is not straightforward to conclude about the relative populations of these channels.
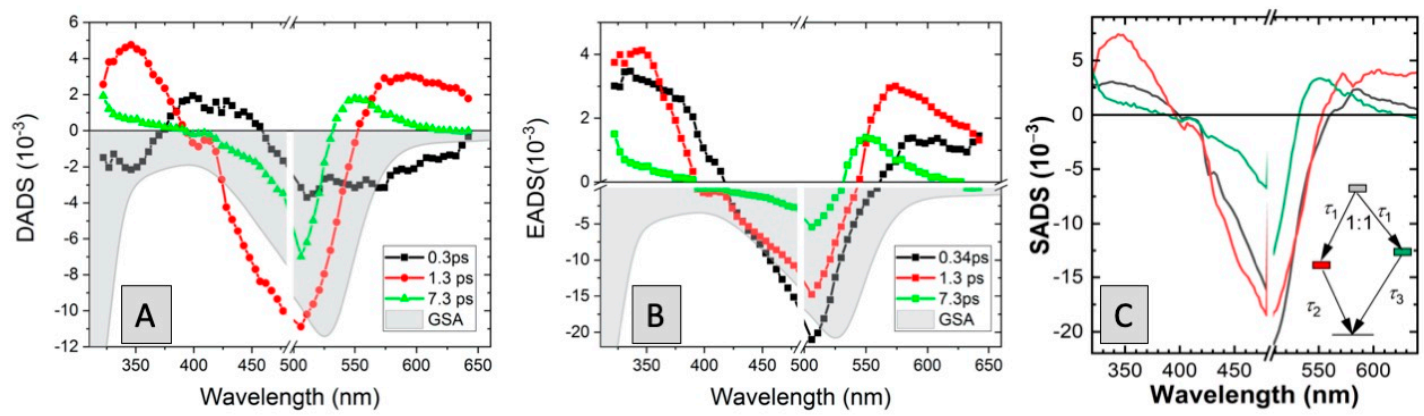

Figure 6. Global and target analysis of the TAS data of compound C1 in ACN. Lifetimes as indicated in the legend, see text for interpretation. (A): Decay-associated difference spectra (DADS) identifying the three global lifetimes $0.3,1.3$ and 7.3 ps, with $10 \%$ error bar. (B): Evolution-associated difference spectra (EADS) for a fully sequential model, Scheme 2. (C): A parallel relaxation model, Scheme 1, with a 50/50 partition between the excited state triplets $\mathrm{T}_{1}$ and $\mathrm{T}_{2}$.

What is the excited state relaxation scenario emerging from these spectroscopic data? The sub-picosecond $\tau_{1}$ is usually assigned to the transition from the optically excited ${ }^{1}$ MLCT to ${ }^{3}$ MLCT and vibrational relaxation of the latter, reflected in the ultrafast rise of ESA below 380 and above $500 \mathrm{~nm}$. The positive DADS of $\tau_{1}$ in the 380-450 nm range can be related to a reshaping of ESA, i.e., vibrational relaxation of ${ }^{3} \mathrm{MLCT}$. On the other hand, the DADS of $\tau_{2}$ and $\tau_{3}$ are very similar to the situation we recently reported for complexes with bidentate ligands [14], where two excited states seem to co-exist, and is rather at odds with the single excited state scenario we reported for tridentate $\mathrm{Fe}-\mathrm{NHC}$ complexes [12]. Indeed, for the latter $\tau_{3}$ was dominant in intensity and $\tau_{2}$ with minor amplitude rather related to structural relaxation in the single excited state. Hence, the TAS data are consistent with the existence of two excited triplet states, $\mathrm{T}_{1}$ and $\mathrm{T}_{2}$, populated via relaxation from ${ }^{1} \mathrm{MLCT}$ and subsequent vibrational cooling during $\tau_{1}$. Their precise nature in terms of diabatic states (MLCT, MC or mixtures of both) cannot be determined from the TAS difference spectra, and will be addressed by TD-DFT calculations (Section 2.3). However, the experimental data suggest a parallel decay back to the ground state $\mathrm{S}_{0}$, according to the following Equation (1):

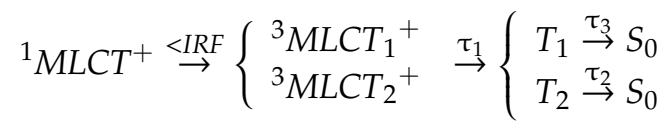

Here, the "+" index denotes vibrationally excited electronic states, inevitably present in the first hundreds of femtoseconds after laser excitation. This scenario was tested with a 50/50 population of T1 and T2 and the species-associated difference spectra (SADS) obtained using GLOTARAN [33] are given in Figure 6C. They provide reasonable difference spectra for these triplet states, with clearly separated bands and transition energies. In the absence of any further knowledge, e.g., from simulations about the ESA spectra of these states, Equation (1) appears to be a viable interpretation of the data. Note that similar excited state branching scenarios, though with different lifetimes and state assignments, were recently published for Fe-NHC complexes with four carbene ligands [34,35].

On the other hand, an alternative purely sequential relaxation scheme can be postulated according to Equation (2):

$$
{ }^{1} \mathrm{MLCT}^{+} \stackrel{<I R F}{\rightarrow}{ }^{3} \mathrm{MLCT} T^{+} \stackrel{\tau_{1}}{\rightarrow} \mathrm{T}_{1} \stackrel{\tau_{2}}{\rightarrow} \mathrm{X} \stackrel{\tau_{3}}{\rightarrow} S_{0}
$$


The corresponding evolution-associated difference spectra (EADS) are given in Figure 6B. The excited state relaxation populates a triplet state $\mathrm{T}_{1}$ within $0.3 \mathrm{ps}$, which decays on a $1.3 \mathrm{ps}$ timescale into a state $X$, which has a 7.3 ps lifetime. While it cannot be excluded that $X$ is an excited state of unknown nature, the EADS of this species suggests its absorption spectrum to be very similar to the GSA of C1, the only differences being a slight 20-30 $\mathrm{nm}$ red-shift of the main transitions (see Supplementary Materials). It is therefore very likely that, in this sequential scenario, $\mathrm{X}$ represents a vibrationally excited, "hot" form of $S_{0}$. Further information comes from TD-DFT calculations, which will be discussed in Section 2.3.

\subsubsection{Fs-TAS of $\mathbf{C} 2$}

C2 dissolved in ACN was excited with $\approx 50$ fs pump pulses at $400 \mathrm{~nm}$, and the pump-induced absorbance changes $\Delta \mathrm{A}$, in the range of 350-650 $\mathrm{nm}$ are displayed in Figure 7A,B together with the sign-inverted ground state absorption spectrum (GSA) in panel A. The TAS data show a negative ground state bleach (GSB) at all delays probed and over the full wavelength range. A small positive $\triangle \mathrm{A}$ on the $0.2 \mathrm{ps}$ spectrum may be due to excited state absorption (ESA) from an early decaying state, but since these data are not corrected for cross-phase modulation around time zero, the assignment is unclear. As shown by the kinetic traces (Figure 7C), the bleach signal increases slightly between time zero and $\approx 1.0 \mathrm{ps}$, and decays thereafter on a time scale longer than the observation window (1.1 ns). Double exponential fits of traces at individual wavelengths, displayed in Figure 7C, yield a GSB rise time $\tau_{1}$ of $0.2-0.5 \mathrm{ps}$, and a decay time $\tau_{2}=3.2 \pm 0.5 \mathrm{~ns}$.
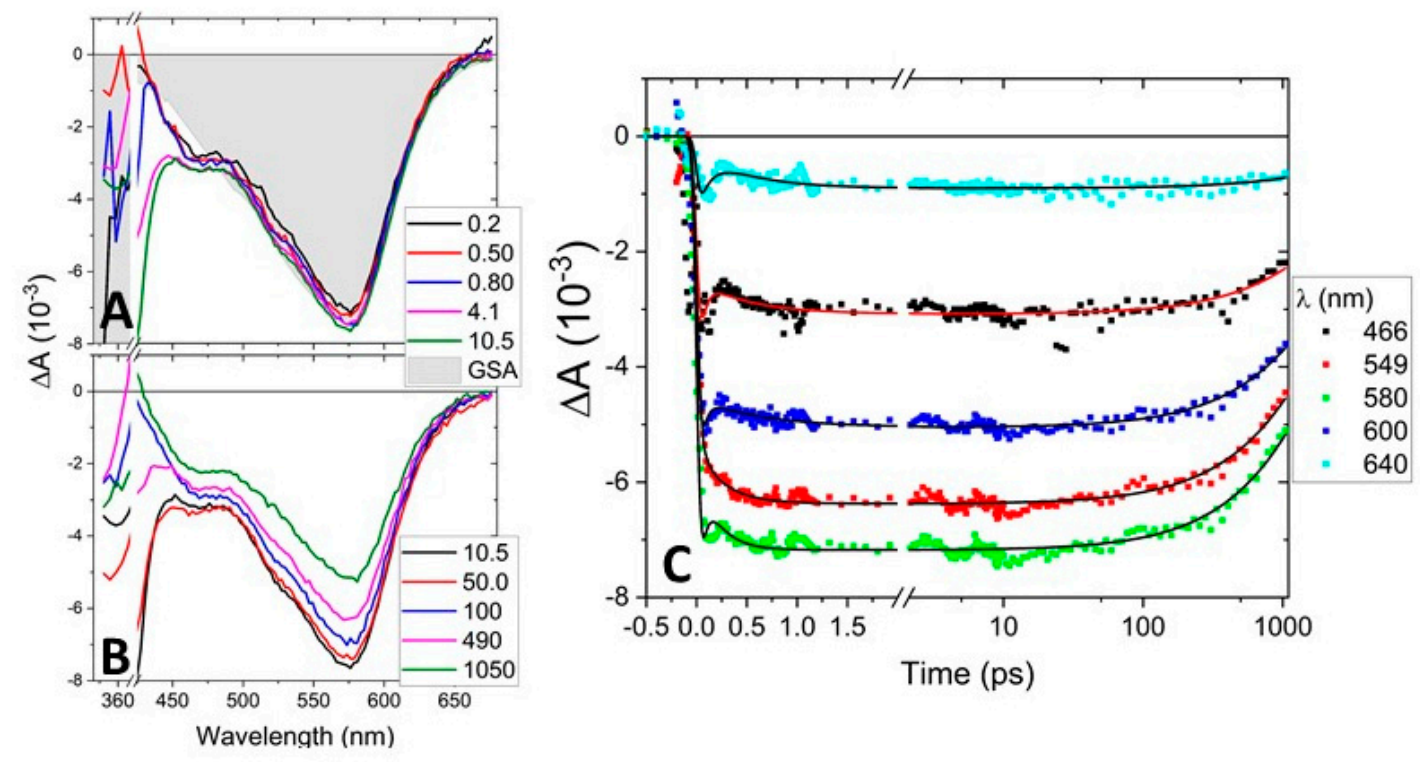

Figure 7. Transient absorption data of $\mathbf{C 2}$. (A,B) time-resolved $\Delta \mathrm{A}$ spectra at delays indicated in the legend (in ps). The region $365-425 \mathrm{~nm}$ is omitted due to excessive pump laser scattering. (C): Kinetic traces at different wavelengths in the main bleach band, together with bi-exponential fits (see text for details). The sharp features at $\approx 0.1$ ps are most likely due to cross phase modulation ("coherent artefact").

Cast in a global lifetime analysis, values of $\tau_{1}=0.45 \pm 0.1 \mathrm{ps}$, and $\tau_{2}=3.0 \pm 0.1 \mathrm{~ns}$ are found. The DADS and the SADS using a sequential relaxation scheme are displayed in Figure S9. The lifetime and $\triangle \mathrm{A}$ spectrum of the long-lived species is consistent with the one observed for the ${ }^{5} \mathrm{MC}$ quintet state of $\left[\mathrm{Fe}(\mathrm{tpy})_{2}\right]^{2+}$ in $\mathrm{H}_{2} \mathrm{O}$ [36], in particular the very weak ESA, if any, in the red part of the spectrum distinguishes it from an ${ }^{3} \mathrm{MLCT}$ state (cf. C1, and other Fe-NHC complexes). Note that the negative $\Delta \mathrm{A}$ signal level $<360 \mathrm{~nm}$ is much smaller than the expected GSB (inverted GSA), pointing to absorption of the MC quintet, in good agreement with reports probing ${ }^{5} \mathrm{MC}$ of $\left[\mathrm{Fe}(\mathrm{tpy})_{2}\right]^{2+}$ down to $290 \mathrm{~nm}$ [37]. 
In analogy to other polypyridyl complexes of $\mathrm{Fe}(\mathrm{II})$, the data are consistent with an ultrafast spin crossover transition from the ${ }^{1 / 3}$ MLCT manifold, identified by the SADS of $\tau_{1}$ (Figure S3). Hence, the relaxation scheme for $\mathbf{C} 2$ is:

$$
{ }^{1} \mathrm{MLCT}^{+} \stackrel{<I R F}{\rightarrow}{ }^{3} \mathrm{MLCT}^{+} \stackrel{\tau_{1}=0.45 p s}{\rightarrow}{ }^{5} \mathrm{MC} \stackrel{\tau_{2}=3.0 n s}{\rightarrow} S_{0}
$$

It must be noted, however, that the ultrafast relaxation into ${ }^{5} \mathrm{MC}$ leads necessarily to a vibrationally excited quintet. The vibrational relaxation time on a similar spin cross-over complex was found to be in the 10 ps range, as identified by fs mid-IR spectroscopy [38]. Apparently, these cooling processes go unnoticed or do not show up with significant spectral changes in the near UV/VIS for C2.

\subsection{Excited-State Decay Mechanism Based on TD-DFT Calculations}

The most relevant electronic states involved in the photoresponses of $\mathbf{C} \mathbf{1}$ and $\mathbf{C} 2$ are displayed in Figure 8. We have adopted the computational methodology used in our previous works on Fe-NHC complexes with bidentate $[11,13,14]$ and tridentate ligands [12] in order to obtain fully comparable results.
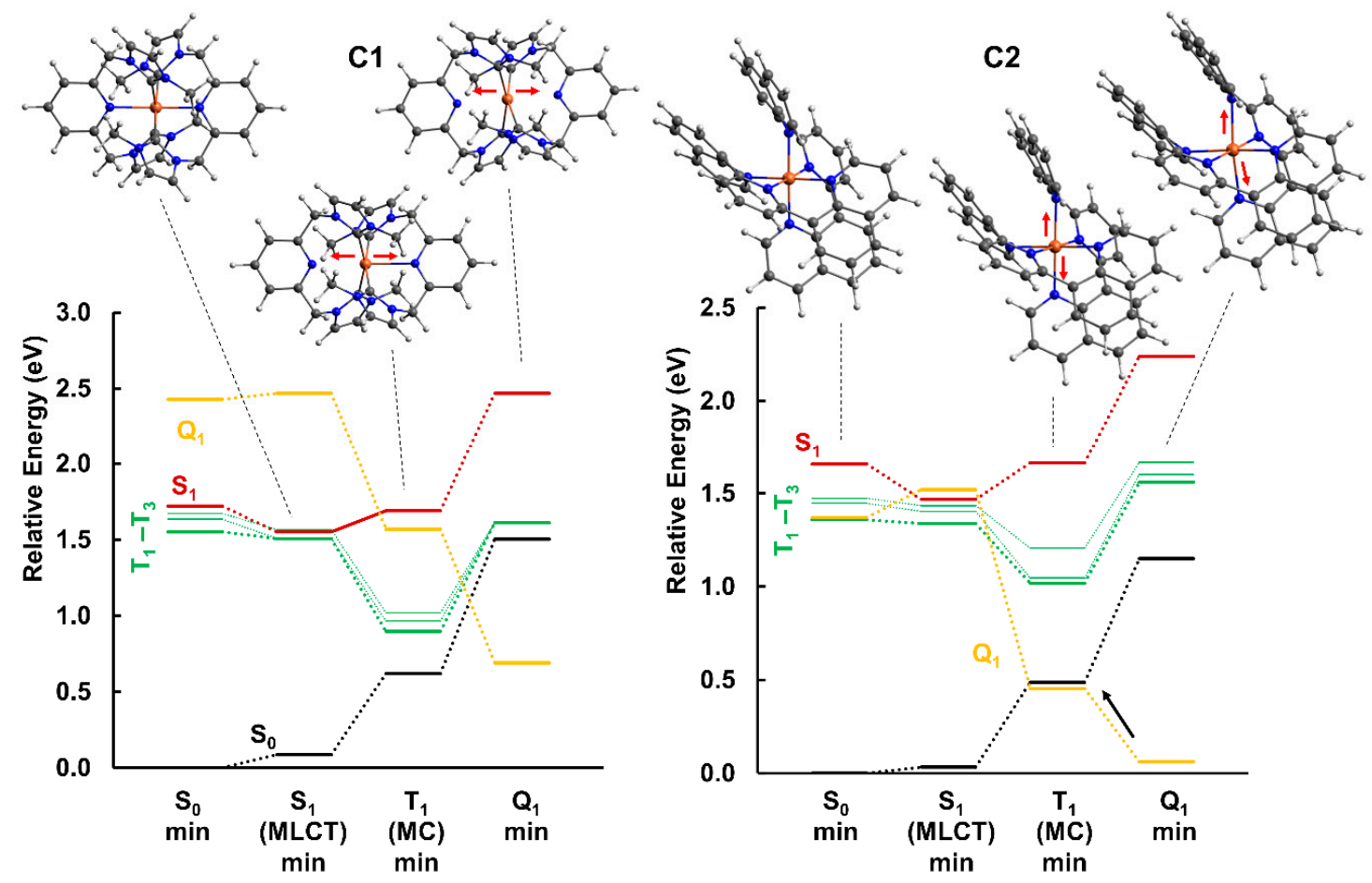

Figure 8. Relative energies of the ground state $\left(\mathrm{S}_{0}\right)$ and the lowest-lying singlet $\left(\mathrm{S}_{1}\right)$, triplet $\left(\mathrm{T}_{1}\right)$ and quintet $\left(Q_{1}\right)$ excited states of complexes $\mathbf{C} \mathbf{1}$ (left) and $\mathbf{C} 2$ (right). $\mathrm{T}_{2}$ and $\mathrm{T}_{3}$ states are also shown in thinner green lines. The dashed lines represent non-connected paths between the different geometries. Red arrows in the 3D molecular representations highlight the $\mathrm{Fe}-\mathrm{N}$ bonds with the greatest elongations during the excited-state decay (Fe-N1 and Fe-N1' for C1, Fe-N1 and Fe-N3 for C2, the values are summarized in Table 4). All energies are relative to the ground state at the corresponding $\mathrm{S}_{0}$ min structure. 
Table 4. Fe-N distances (in $\AA$ ) corresponding to the structures displayed in Figure 8.

\begin{tabular}{|c|c|c|c|c|}
\hline $\mathbf{F e}-\mathbf{N}$ & $S_{0} \min$ & $S_{1} \min$ & $\mathrm{T}_{1} \min$ & $Q_{1} \min$ \\
\hline \multicolumn{5}{|c|}{$\mathrm{C} 1$} \\
\hline $\mathrm{Fe}-\mathrm{N} 1$ & 2.120 & 2.151 & 2.604 & 2.491 \\
\hline $\mathrm{Fe}-\mathrm{N} 1^{\prime}$ & 2.122 & 2.042 & 2.417 & 2.490 \\
\hline \multicolumn{5}{|c|}{$\mathrm{C} 2$} \\
\hline $\mathrm{Fe}-\mathrm{N} 1$ & 2.013 & 2.003 & 2.281 & 2.190 \\
\hline $\mathrm{Fe}-\mathrm{N} 2$ & 1.975 & 1.960 & 1.955 & 2.179 \\
\hline $\mathrm{Fe}-\mathrm{N} 3$ & 2.013 & 2.019 & 2.283 & 2.189 \\
\hline $\mathbf{F e}-\mathbf{N} 1^{\prime}$ & 2.013 & 2.010 & 2.121 & 2.188 \\
\hline $\mathrm{Fe}-\mathrm{N} 2^{\prime}$ & 1.976 & 1.973 & 1.937 & 2.179 \\
\hline $\mathrm{Fe}-\mathrm{N} 3^{\prime}$ & 2.013 & 2.024 & 2.120 & 2.191 \\
\hline
\end{tabular}

As in other transition metal complexes, light absorption populates bright high-lying ${ }^{1} \mathrm{MLCT}$ states of $\mathbf{C} 1$. As commented in the previous sections, ultrafast intersystem crossing leads to the population of the triplet ${ }^{3} \mathrm{MLCT}$ manifold in a sub-picosecond regime, followed by vibrational relaxation to the lowest-lying ${ }^{3} \mathrm{MLCT}$ state $\left(\mathrm{T}_{1}\right)$. From a potential energy surface (PES) perspective, all these phenomena take place in regions close to Franck-Condon and $S_{1}$ min areas, in which the ${ }^{1}$ MLCT and ${ }^{3} \mathrm{MLCT}$ states are also close in energy (see Figure 8). The term $S_{1}$ min areas refer to the PES regions where the energy of the $S_{1}$ state is minimum. On longer time scales, the triplet state must evolve to reach non-adiabatic crossing points with the ground state that mediate non-radiative decay channels. These mechanisms are intrinsically different between Fe-NHC complexes with bidentate $[11,13,14]$ and tridentate [12] ligands and have different implications for the longer ESA components $\tau_{2}$ and $\tau_{3}$. In the former type of complexes, relaxation of the lowest-lying triplet state $\mathrm{T}_{1}$ leads to a ${ }^{3} \mathrm{MC}$ region through a barrierless path encompassing an extended area of spin-crossover character, i.e., an area where $\mathrm{S}_{0}$ lies above $\mathrm{T}_{1}$, in which the system can be trapped for several picoseconds [13]. On the contrary, in complexes with tridentate ligands, the $\mathrm{T}_{1}$ relaxation leads to a well-defined ${ }^{3} \mathrm{MLCT}$ minimum close to the Franck-Condon region [12]. The stretching of $\mathrm{Fe}-\mathrm{N}$ bonds, always involved in the stabilization of the dissociative ${ }^{3} \mathrm{MC}$ states, is clearly the dominant degree of freedom in driving the excited state decay. Due to the different topology of the PESs, $\mathrm{Fe}-\mathrm{N}$ bonds are spontaneously stretched in the triplet manifold of complexes with bidentate ligands, while this molecular motion has an energy cost in $\mathrm{Fe}-\mathrm{NHC}$ systems with tridentate ligands, explaining the triplet lifetimes of tens of picoseconds in the latter [12].

Despite the tridentate coordination, the ES decay mechanism of C1 lies in between these two extreme cases and somehow closer to the bidentate type mechanism. The $\mathrm{T}_{1}$ min has a clear ${ }^{3} \mathrm{MC}$ nature (see Figure 9), with Fe-N distance stretched up to $2.60 \AA$ (see Table 4). As a matter of fact, the $\mathrm{T}_{1}$ min geometry is close to but does not perfectly represent a singlet-triplet crossing (STC) with $\mathrm{S}_{0}$, since the singlet-triplet energy gap is still $0.28 \mathrm{eV}$, although this relatively low energy splitting suggests that the STC must be in the surroundings. As a matter of fact, the $T_{1}$ potential energy surface shown in Figure S10 confirms the access to the singlet-triplet crossing region with the ground state with an energy barrier $<0.05 \mathrm{eV}$. On the other hand, the energy difference between the $\mathrm{T}_{1}-\mathrm{T}_{3}$ states at the $\mathrm{T}_{1}$ min region is smaller as compared to that of previous bidentate Fe-NHC complexes, supporting a possible sequential decay mechanism $\left(T_{1} / T_{2} / T_{3} \rightarrow S_{0}\right)$ in which $\tau_{2}$ is ascribed to the population of the ground state and $\tau_{3}$ belongs to vibrational relaxation of $S_{0}$. A parallel mechanism like the one proposed for pure bidentate complexes (see Scheme 1 and refs $[11,13,14,39]$, in which the $T_{1}$ and $T_{2}$ states are associated to different ES paths operating in parallel, cannot be excluded, although it seems less plausible in this particular case given the $T_{1}-T_{3}$ energy degeneracy at $S_{1}$ min and $T_{1}$ min regions. 
C1

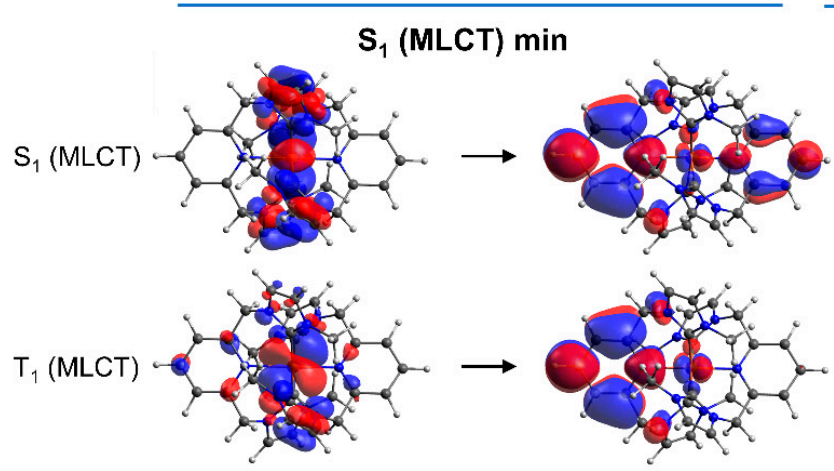

$T_{1}(M C) \min$

$\mathrm{S}_{1}(\mathrm{MC})$

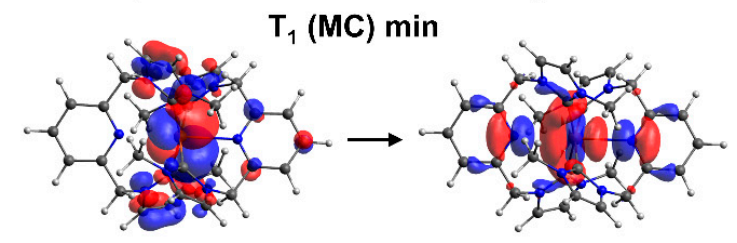

$\mathrm{T}_{1}(\mathrm{MC})$

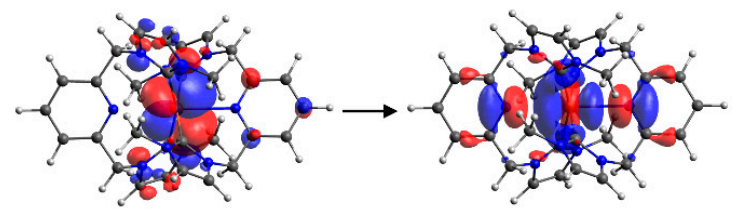

C2

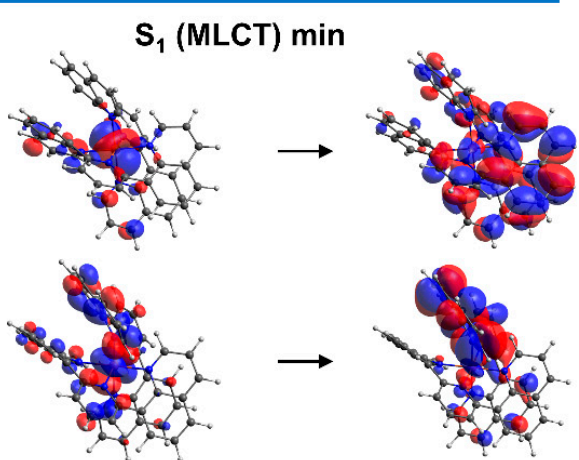

$T_{1}(M C) \min$
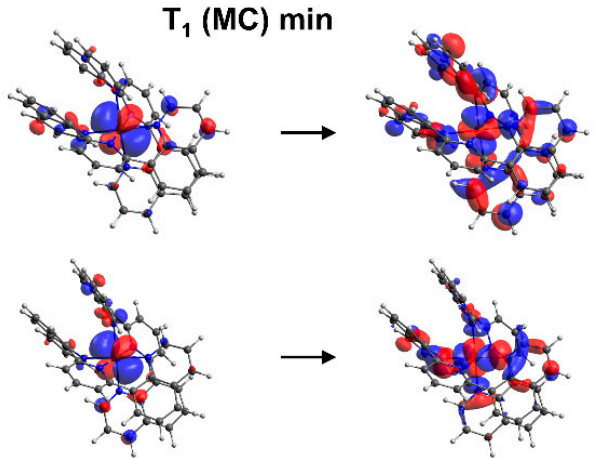

Figure 9. Natural transition orbitals (NTOs) of the $S_{1}$ and $T_{1}$ states at their corresponding optimized geometries for C1 (left) and C2 (right).

The analysis of the photodynamics of $\mathbf{C 1}$ is also of particular value since it reinforces important general conclusions about the photophysics of this type of Fe(II) complexes. In particular, the flexibility added by the presence of alkyl spacers between the pyridine and imidazole rings opens ES decay paths that are forbidden for the more rigid tridentate complex, that is, longer Fe-N elongations leading to accessible ${ }^{3} \mathrm{MC}$ minima. This is reflected in the TAS signals (two long components in bidentates vs. one component in tridentates) and in the photochemical landscape shown in Figure 8. Hence, a subtle equilibrium between the ideality of the octahedral coordination, destabilizing the ${ }^{3} \mathrm{MC}$ states in the Franck-Condon region, and limited flexibility, hampering an efficient population of ${ }^{3} \mathrm{MC}$ states at regions far from the Franck-Condon area via Fe-N elongations, should be carefully considered when designing photoactive iron complexes.

On the contrary, the ES decay mechanism of $\mathbf{C 2}$, as also highlighted by TAS results, follows a completely different scenario. A major difference as compared to $\mathbf{C} \mathbf{1}$ is the pivotal role played by the much more stable $Q_{1}$ state, which is degenerated with $T_{1}$ already at the Franck-Condon geometry (see Figure 8). Whereas the optimization of the $\mathrm{S}_{1}\left({ }^{1} \mathrm{MLCT}\right)$ state destabilizes $\mathrm{Q}_{1}$, this state is on the contrary greatly stabilized with the Fe-N stretching associated to the $\mathrm{T}_{1}$ relaxation. Indeed, the $\mathrm{Q}_{1}$ state becomes degenerated with the ground state at the $\mathrm{T}_{1}$ min region, which is of ${ }^{3} \mathrm{MC}$ nature (see Figure 9). Full optimization of the $Q_{1}$ state gives the $Q_{1} \mathrm{~min}$, in which the state is at a relative energy close to that of the ground state at its corresponding equilibrium geometry, hence fully justifying the observed light-induced spin crossover capabilities of $\mathbf{C} 2$.

Therefore, as stated above, the data presented in Figure 8 indicate that the $\mathrm{Q}_{1}$ state is the main actor of C2's photoresponse, in coherence with the TAS analysis depicted above. This state is populated in the Franck-Condon region or in the surroundings in $\sim 0.3 \mathrm{ps}$ and is expected to rapidly evolve towards the $\mathrm{Q}_{1}$ min region. At this region, the $\mathrm{S}_{0}$ is not accessible (note that its relative energy is of $1.15 \mathrm{eV}$, more than $1 \mathrm{eV}$ above $\mathrm{Q}_{1}$ ), and therefore one can expect a significant barrier (at least $0.5 \mathrm{eV}$, according to the solid black arrow shown Figure 8) to repopulate the ground state. This description is in good agreement with the long 3.0 ns lifetime measured experimentally for the quintuplet state. 


\section{Materials and Methods}

\subsection{General Information}

Solvents and commercially available reagents were used as received. Thin layer chromatography (TLC) was performed by using silica gel 60 F-254 (Merck) plates and visualized under UV light. Chromatographic purification was performed by using silica gel 60 (0.063-0.2 mm/70-230 mesh). ${ }^{1} \mathrm{H}(400 \mathrm{MHz})$ and ${ }^{13} \mathrm{C}$ NMR (100 MHz) spectra were taken on a DRX400 Bruker spectrometer at ambient temperature. The chemical shifts $(\delta)$ were calibrated by using either tetramethylsilane (TMS) or signals from the residual protons of the deuterated solvents and are reported in parts per million (ppm) from low to high field. High-resolution mass spectrometry (HRMS) data was obtained by using Bruker micrOTOF-Q spectrometer. UV vis spectra were recorded in a $1 \mathrm{~cm}$ path length quartz cell on a LAMBDA 1050 (PerkinElmer), spectrophotometer. Cyclic voltammetry was performed on a Radiometer PST006 potentiostat using a conventional three-electrode cell. The saturated calomel electrode (SCE) was separated from the test compartment using a bridge tube. The solutions of studied complexes $(0.2 \mathrm{mM})$ were purged with argon before each measurement. The test solution was acetonitrile containing $0.1 \mathrm{M} \mathrm{Bu}_{4} \mathrm{NPF}_{6}$ as supporting electrolyte. The working electrode was a vitreous carbon rod $\left(1 \mathrm{~cm}^{2}\right)$ wire, and the counter-electrode was a $1 \mathrm{~cm}^{2} \mathrm{Pt}$ disc. After the measurement, ferrocene $(\mathrm{Fc})$ was added as the internal reference for calibration. All potentials were quoted versus SCE. In these conditions the redox potential of the couple Fc+/Fc was found at $0.39 \mathrm{~V}$. In all the experiments the scan rate was $100 \mathrm{mV} . \mathrm{s}^{-1}$.

\subsection{Xray Diffraction}

Two single crystals of complexes C1 and C2 were selected and measured with a Rigaku Oxford Diffraction SuperNova 4-circles diffractometer. This diffractometer was equipped with a microfocus X-ray source with a Molybdenum anode $(\operatorname{MoK} \alpha, \lambda=0.71073 \AA)$ and an Atlas CCD detector. An Oxford Cryosystems Cryostream nitrogen blower was used to fix the sample temperature at $100 \mathrm{~K}$ for $\mathrm{C} 1$ and $110 \mathrm{~K}$ for C2. Using Olex2 software [40], structures were solved with XT structure solution program [41] and structures were refined with the XL refinement package [41] by using Least Square minimization. CCDC 1992132 (C1) and CCDC 1982173 (C2) contain the supplementary crystallographic data for this paper. These data are provided free of charge by the Cambridge Crystallographic Data Centre.

\subsection{Ultrafast Transient Absorption Spectroscopy}

An amplified 5kHz Ti: sapphire laser generates $30 \mathrm{fs} 0.5 \mathrm{~mJ}$ pulses to pump a commercial optical parametric amplifier (TOPAS: Light Conversion), from which 50-60 fs pulses are derived to excite the samples: $495 \mathrm{~nm}$ for $\mathbf{C 1}$, and $400 \mathrm{~nm}$ for C2. A white light continuum is generated in a $2 \mathrm{~mm}$ thick $\mathrm{CaF}_{2}$ crystal, mounted on an oscillating loudspeaker to reduce photo-damage. The white light is optimized for minimized fluctuations ( $\mathrm{rms}<0.4 \%$ at $220 \mathrm{~Hz}$ ). The beam is split in two: the probe that is sent through the sample, and a reference beam is used for measuring and compensating the white-light intensity fluctuations. The polarization of the probe beam is set at magic angle $\left(54.7^{\circ}\right)$ with respect to the pump. A $1 \mathrm{~mm}$ path length cuvette in fused silica contains the complexes dissolved in $\mathrm{CH}_{3} \mathrm{CN}$. Time-resolved spectra $\mathrm{I}(\lambda)$ are acquired in a range $\approx 300 \mathrm{~nm}$ wide window with an adjustable central wavelength as a function of pump-probe delay, by a combination of $25 \mathrm{~cm}$ focal length spectrometer (resolution $2 \mathrm{~nm}$ ) and a Peltier-cooled CCD with $220 \mathrm{~Hz}$ acquisition rate. A second chopper blocks the pump beam at $110 \mathrm{~Hz}$ and a home-made software computes and displays the differential spectra $\Delta A=-\log _{10}\left(\frac{I_{\text {pump-on }}}{I_{\text {pump-off }}}\right)$. A solvent-only sample is measured, and the data are processed to (i) remove a residual signal background at negative delay times, (ii) the solvent Raman signal and the coherent interactions of the pump and probe in the cell (except for C2), (iii) to correct for the group velocity dispersion of the probe beam, characterized in the solvent-only data set. The temporal resolution is determined by the $50 \pm 5 \mathrm{fs}$ FWHM of the solvent Raman response. Data are 
fitted at individual wavelengths according to $\Delta A(\lambda, t)=\operatorname{IRF}\left(t_{0}, \sigma\right) \otimes\left(A_{0}+\sum_{i=1}^{n} A_{i}(\lambda) e^{-t / \tau_{i}(\lambda)}\right),(1)$ a sum of n-exp functions and an un-resolved contribution (A0), convoluted with a Gaussian instrument response function (IRF, $\sigma=35-50 \mathrm{fs}$, FWHM). Although data are chirp-corrected and $\mathrm{t} 0$, is adjustable for each wavelength. Global and target analysis was performed with the software packages OPTIMUS [32] and GLOTARAN [33].

\subsection{Computational Details}

The computational protocol has been widely validated in previous works and it will be only summarized here [11-14,39,42]. Unless otherwise stated, all calculations have been performed using the Gaussian 16 program [43]. The ground state geometries have been optimized using the DFT/B3LYP method, whereas the $S_{1}$ state has been optimized using TD-DFT in combination with the pure HCTH functional [44]. The $T_{1}$ and $Q_{1}$ states have been optimized using the unrestricted $\mathrm{uDFT} / \mathrm{HCTH}$ method. All optimizations have been performed employing the $6-31+G(d, p)$ basis set. Later, single-point calculations with the larger $6-311 G(d, p)$ basis set have been performed on top of the converged geometries to obtain the final energies displayed in Figure 8. The energies of $S_{1}$ and $T_{1}$ have been obtained with the TD-DFT/HCTH method, while the energies of $\mathrm{Q}_{1}$ have been determined making use of the $\mathrm{uDFT} / \mathrm{HCTH}$ ansatz. Solvent effects (acetonitrile) have been included by means of the polarizable continuum model. The Tamm-Dancoff approximation has been used in all TD-DFT calculations [45]. For $\mathbf{C}$, due to the inherent $\pi$-stacking interaction of the ligands, empirical dispersion has been included in all calculations through Grimme's original D3 damping function [46]. Analysis of the nature of the excitations (Figure 9) have been performed by computing the natural transition orbitals (NTOs) [47] with the NANCY_EX code $[48,49]$.

\subsection{Synthesis of Ligands and Complexes}

\subsubsection{Synthesis of Ligands}

Synthesis of L1 [31]. A solution of 2,6-bis(bromomethyl)pyridine (1.337 g, $5.0 \mathrm{mmol})$ and 1-methylimidazole $(0.831 \mathrm{~g}, 10.0 \mathrm{mmol})$ was stirred in dioxane $(80 \mathrm{~mL})$ at $100^{\circ} \mathrm{C}$ for $12 \mathrm{~h}$. After cooling, the formed solid was collected and purified by repetitive precipitation from $\mathrm{MeOH} / \mathrm{Et} 2 \mathrm{O}$ mixtures and finally by recrystallization from $\mathrm{CH}_{2} \mathrm{Cl}_{2} / \mathrm{Et}_{2} \mathrm{O}$. The product was then collected and solubilized in a small amount of water, then precipitated using a saturated aqueous solution of $\mathrm{KPF}_{6}$ to give $\mathbf{L 1}(2.27 \mathrm{~g}$, $80 \%) .{ }^{1} \mathrm{H}-\mathrm{NMR}\left(\mathrm{CD}_{3} \mathrm{CN}, 400 \mathrm{MHz}\right): \delta 8.47(\mathrm{~s}, 2 \mathrm{H}), 7.90(\mathrm{t}, J=7.8 \mathrm{~Hz}, 1 \mathrm{H}), 7.44(\mathrm{~d}, J=7.8 \mathrm{~Hz}, 2 \mathrm{H}), 7.35$ $(\mathrm{s}, 4 \mathrm{H}), 5.38(\mathrm{~s}, 4 \mathrm{H}), 3.85(\mathrm{~s}, 12 \mathrm{H}) \mathrm{ppm}$.

Synthesis of dqp [18]. An oven-dried flask was charged with 8- quinoline boronic acid (413 mg, $2.39 \mathrm{mmol}), 2,6$-dibromo-pyridine (265mg, 1.12mmol), Pd(dba)2 (13mg, 0.023mmol), 2-dicyclohexylphosphino-2', 6'-dimethoxybiphenyl $(0.019 \mathrm{~g}, 0.046 \mathrm{mmol})$ and grinded $\mathrm{K}_{3} \mathrm{PO}_{4}(2.27 \mathrm{~g}$, $10.7 \mathrm{mmol})$. The flask was evacuated and charged with $\mathrm{N}_{2}$. Dry toluene $(10 \mathrm{~mL})$ was added via a syringe and the resulting suspension was stirred at $100 \circ \mathrm{C}$ for $15 \mathrm{~h}$. The mixture could cool to room temperature, diluted with $\mathrm{CH}_{2} \mathrm{Cl}_{2}(30 \mathrm{~mL})$ and filtered. The solvent was removed and the remaining solid purified by column chromatography using silica gel and $2.5 \% \mathrm{MeOH} / \mathrm{CH}_{2} \mathrm{Cl}_{2}$ as eluent to give dqp as an off-white solid (244mg, 65\%). ${ }^{1} \mathrm{H}-\mathrm{NMR}\left(\mathrm{CDCl}_{3}, 400 \mathrm{MHz}\right.$ ): $\delta 9.00(\mathrm{dd}, J=4.2,1.9 \mathrm{~Hz}, 2 \mathrm{H})$, $8.28(\mathrm{dd}, J=7.3,1.5 \mathrm{~Hz}, 2 \mathrm{H}), 8.24(\mathrm{dd}, J=8.3,1.9 \mathrm{~Hz}, 2 \mathrm{H}), 8.13(\mathrm{~d}, J=7.7 \mathrm{~Hz}, 2 \mathrm{H}), 7.96(\mathrm{t}, J=7.7 \mathrm{~Hz}$, $1 \mathrm{H}), 7.89(\mathrm{dd}, J=8.2,1.5 \mathrm{~Hz}, 2 \mathrm{H}), 7.67(\mathrm{dd}, J=8.2,7.3 \mathrm{~Hz}, 2 \mathrm{H}), 7.46(\mathrm{dd}, J=8.3,4.2 \mathrm{~Hz}, 2 \mathrm{H}) \mathrm{ppm}$.

\subsubsection{Synthesis of Complexes}

Synthesis of C1. To a solution of $\mathbf{L 1}(0.129 \mathrm{~g}, 0.231 \mathrm{mmol})$ in $2 \mathrm{~mL}$ of anhydrous DMF was added $\mathrm{FeBr}_{2}(15 \mathrm{mg}, 0.115 \mathrm{mmol})$ and degassed the mixture with $\mathrm{N}_{2}$ for $10 \mathrm{~min}$. Then $t$-BuOK was added (104 mg, $0.927 \mathrm{mmol}$ ) to the above mixture and stirred at $0{ }^{\circ} \mathrm{C}$ and temperature left slowly rising to room temperature. A saturated solution of $\mathrm{KPF}_{6}$ was added $(10 \mathrm{~mL})$, and the precipitate was collected by filtration. Then the crude was further purified on silica gel column chromatography using 
acetone $/ \mathrm{H}_{2} \mathrm{O} / \mathrm{KNO}_{3}$ (sat) = 10:3:3 mixture. The pink fraction was collected and after the evaporation of acetone, the left solution was treated with a saturated solution of $\mathrm{KPF}_{6}$. $\mathbf{C 1}(20 \mathrm{mg}, 19 \%)$ was finally obtained after filtration. ${ }^{1} \mathrm{H}-\mathrm{NMR}\left(\mathrm{CD}_{3} \mathrm{CN}, 400 \mathrm{MHz}\right): \delta 7.58(\mathrm{t}, 2 \mathrm{H}, J=7.7 \mathrm{~Hz}), 7.30(\mathrm{~d}, 4 \mathrm{H}, J=7.7$ $\mathrm{Hz}), 7.07(\mathrm{~d}, 4 \mathrm{H}, J=1.9 \mathrm{~Hz}), 6.67(\mathrm{~d}, 4 \mathrm{H}, J=1.9 \mathrm{~Hz}), 5.41(\mathrm{~s}, 4 \mathrm{H}), 3.40(\mathrm{~s}, 4 \mathrm{H}), 2.05(\mathrm{~s}, 12 \mathrm{H}) \mathrm{ppm}$. ${ }^{13} \mathrm{C}-\mathrm{NMR}\left(\mathrm{CD}_{3} \mathrm{CN}, 100 \mathrm{MHz}\right): \delta 191.4,157.3,137.3,126.3,124.2,120.1,53.5,34.5$. HR-MS (ESI) calcd for $\mathrm{C}_{30} \mathrm{H}_{34} \mathrm{FeN}_{10} \mathrm{P}_{2} \mathrm{~F}_{12} \mathrm{~m} / \mathrm{z}=295.1153\left[\mathrm{M}-2 \mathrm{PF}_{6}\right]^{2+}$. Found: 295.1145 .

Synthesis of C2. A $5 \mathrm{~mL}$ microwave tube was charged with dqp (65 mg, $0.195 \mathrm{mmol}$ ) and $\mathrm{FeBr}_{2}$ (20 $\mathrm{mg}, 0.093 \mathrm{mmol})$. After addition of DMF $(3 \mathrm{~mL})$ the tube was sealed and heated for $4 \mathrm{~h}$ using microwave heating $(60 \mathrm{~W})$. A saturated solution of $\mathrm{KPF}_{6}$ was added $(10 \mathrm{~mL})$, and the precipitate was collected by filtration. Then the crude was further purified on silica gel column chromatography using Acetone $/ \mathrm{H}_{2} \mathrm{O} / \mathrm{KNO}_{3}$ (sat) $=10: 3: 3$ mixture. The dark pink fraction was collected and after the evaporation of acetone, the left solution was treated with a saturated solution of $\mathrm{KPF}_{6} \cdot \mathrm{C} 2(28 \mathrm{mg}$, $30 \%)$ was finally obtained after filtration. ${ }^{1} \mathrm{H}-\mathrm{NMR}(400 \mathrm{MHz}, \mathrm{CD} 3 \mathrm{CN}): \delta 8.17(\mathrm{dd}, J=8.2,7.8 \mathrm{~Hz}$, $2 \mathrm{H}), 8.07(\mathrm{~m}, 8 \mathrm{H}), 7.89(\mathrm{~m}, 4 \mathrm{H}), 7.73(\mathrm{dd}, J=7.5,1.3 \mathrm{~Hz}, 4 \mathrm{H}), 7.68(\mathrm{dd}, J=8.3,1.3 \mathrm{~Hz}, 4 \mathrm{H}), 7.45(\mathrm{dd}$, $J=8.3,7.5 \mathrm{~Hz}, 4 \mathrm{H}), 7.05(\mathrm{dd}, J=7.9,5.3 \mathrm{~Hz}, 4 \mathrm{H}) \mathrm{ppm} .{ }^{13} \mathrm{C}-\mathrm{NMR}$ (DMSO-d6, $100 \mathrm{MHz}$ ): $\delta 164.50$, $164.25,161.34,149.95,138.89,138.68,132.36,130.84,128.10,127.88,127.32,126.25$. HR-MS (ESI) calcd for $\mathrm{C}_{46} \mathrm{H}_{30} \mathrm{FeN}_{6} \mathrm{P}_{2} \mathrm{~F}_{12} \mathrm{~m} / \mathrm{z}=361.0935\left[\mathrm{M}-2 \mathrm{PF}_{6}\right]^{2+}$. Found: 361.0944 .

\section{Discussion and Conclusions}

The present study of Fe(II) homoleptic tridentate complexes C1 and C2 with octahedral coordination symmetry aimed at providing evidence for the effect of a larger ligand field splitting on the excited state (ES) dynamics, in particular aiming at obtaining longer-lived ${ }^{3}$ MLCT states. The change in geometry had a positive effect on the absorption properties inducing notable red shifts of the Fe-pyridine MLCT absorption bands compared with the non-octahedral C0, in agreement with the decrease of the HOMO-LUMO gap also confirmed by cyclic voltammetry. However, as pointed out above, the ligand modifications also bring about a larger conformational flexibility, the effect of which appears to dominate the ES quantum dynamics.

When comparing $\mathbf{C} \mathbf{1}$ with the proto-typical $\mathbf{C 0}\left(\left[\mathrm{Fe}(\mathrm{bmip})_{2}\right]^{2+}\right)$ two important differences are observed. First, the ES lifetime of $\mathbf{C} \mathbf{1}$ is roughly six times shorter than that of $\mathbf{C}$. The TD-DFT calculations indicate that, due to the higher ligand flexibility, the barrier hindering the relaxation of ${ }^{3} \mathrm{MLCT}$ into the metal-centered ${ }^{3} \mathrm{MC}$ in $\left[\mathrm{Fe}(\mathrm{bmip})_{2}\right]^{2+}$ is lowered in $\mathrm{C} 1$, leading to a faster ES deactivation (Figure 10 center). The TD-DFT calculations indicate that, most likely, one single triplet state minimum of ${ }^{3} \mathrm{MC}$ character is transiently populated (Figure 8) hinting to the "sequential decay" scenario being more plausible. Secondly, a strongly damped excited state vibrational coherence is observed with a frequency of $55-65 \mathrm{~cm}^{-1}$, in addition to ground state vibrations in the range of $\approx 350$ $\mathrm{cm}^{-1}$ (cf. Figure S8). The higher frequency is in the usual range of $\mathrm{Fe}-\mathrm{N}$ or $\mathrm{Fe}-\mathrm{C}$ stretch vibrations, and the $60 \mathrm{~cm}^{-1}$ is similar to the low frequency breathing mode identified for $\mathrm{C} 0$ at $110 \mathrm{~cm}^{-1}$ [50]. It was recently identified to be associated with vibrationally coherent population of ${ }^{3} \mathrm{MC}$ through ultrafast branching from the ${ }^{1}$ MLCT manifold in C0 [36]. We rather attribute it to the initially populated ${ }^{3}$ MLCT. In any case, its existence and lower frequency point to a higher flexibility of the ligands of $\mathbf{C} \mathbf{1}$ as compared to $\mathbf{C}$. For $\mathbf{C 2}$, the relaxation from ${ }^{3} \mathrm{MLCT}$ into the metal-centered ${ }^{3} \mathrm{MC}$ and ${ }^{5} \mathrm{MC}$ states (Figure 10, left) seems to be almost unaffected since the $0.45 \mathrm{ps}$ lifetime is only slightly longer than the one observed for $\left[\mathrm{Fe}(\text { tpy })_{2}\right]^{2+}[8]$. 

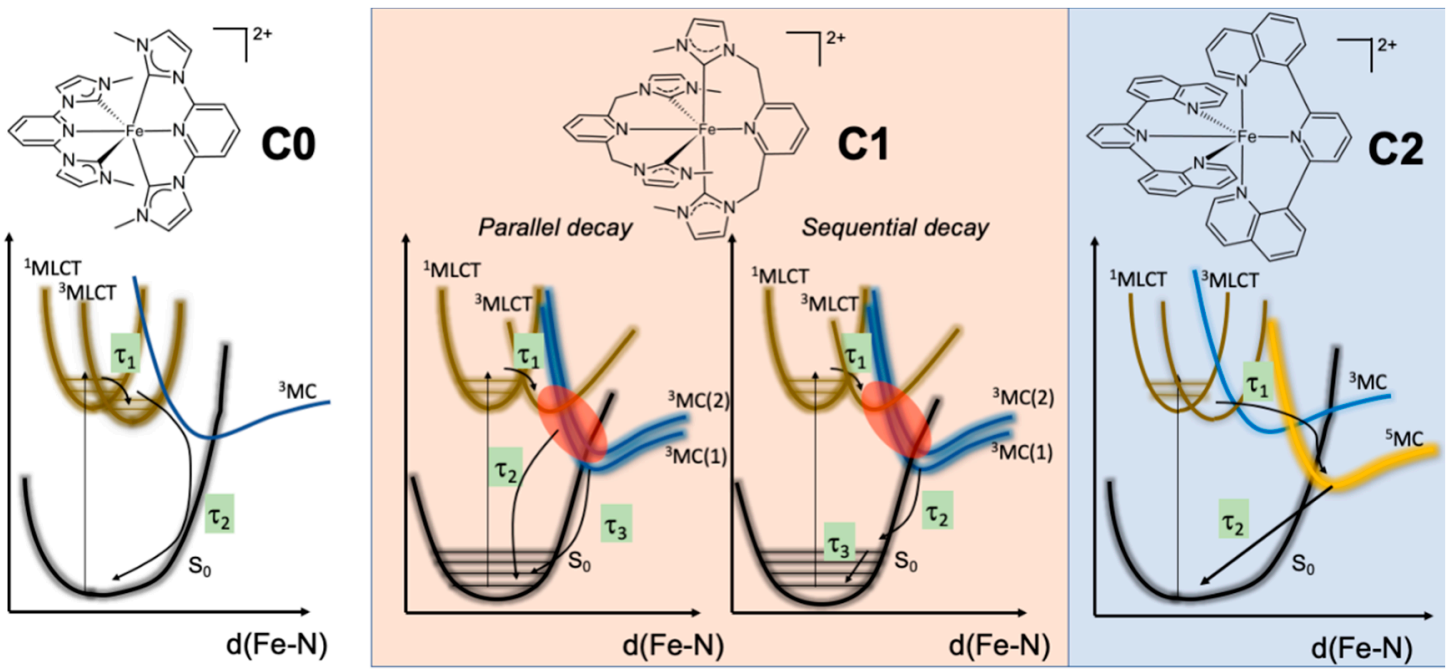

Figure 10. Excited state relaxation schemes for the three complexes $\mathbf{C} \mathbf{0}, \mathbf{C} \mathbf{1}$ and $\mathbf{C} \mathbf{2}$, as inferred from TAS data and TD-DFT calculations. Lifetimes and arrows identify the relevant steps of internal conversion and intersystem crossing. (Left): in $\mathbf{C} 0$, the rigid tridentate structure imposes a slight barrier on the ${ }^{3}$ MLCT- ${ }^{3}$ MC relaxation and stabilizes ${ }^{3}$ MLCT for $9-10$ ps [8]. (Center): the larger ligand flexibility in C1 reduces this barrier and leads to a region of adiabatic mixing between ${ }^{3} \mathrm{MLCT}$ and ${ }^{3} \mathrm{MC}$ (red ellipse). The sketch labeled "parallel decay" refers to Equation (1) (Section 2.2.1). However, our calculations indicate that one single triplet state minimum of ${ }^{3} \mathrm{MC}$ character is transiently populated (Figure 8) hinting to the "sequential decay" scenario being more plausible (Equation (2), Section 2.2.1). (Right): C2 is a photo-induced spin crossover complex like $\left[\mathrm{Fe}(\mathrm{tpy})_{2}\right]^{2+}$. Note that for $\mathbf{C} 0$, the recently revealed parallel population of ${ }^{3} \mathrm{MLCT}$ and ${ }^{3} \mathrm{MC}[35]$ is not represented for simplicity.

In summary, the comparison of the photophysics of $\mathbf{C} \mathbf{1}$ and $\mathbf{C} 2$ evidences important aspects about the $\mathrm{Fe}(\mathrm{II})$ coordination sphere directly impacting ES decay mechanisms and ES lifetimes of Fe-NHC complexes. The main conclusion is that the destabilization of ${ }^{3} \mathrm{MC}$ states at the Franck-Condon region does not guarantee longer triplet MLCT lifetimes since these states quickly relax out of this region if the system is flexible enough, as demonstrated by the current $\mathbf{C} \mathbf{1}$ complex. A similar conclusion was drawn from our previous comparison of bidentate vs. tridentate coordination where the associated rigidity dictates the participation of the triplet states and their ability to stretch Fe-N bonds [14]. Longer ES lifetimes may be achieved by blocking the elongations of the Fe-N bonds [51] or through their substitution by more photoresistant bonds such as Fe-C ones [15,52-54].

In the case of $\mathbf{C 2}$, while the increase of the rigidity of the molecular scaffold could allow the improvement of the photophysical properties, the presence of six Fe-N bonds strongly diminishes the ligand-field splitting and hence strongly shortens the ES lifetime due to the stabilization of the metal centered quintet state that is actively participating in the relaxation. All in all, these contrasting observations clearly points to the subtle equilibrium between the different electronic and geometrical factors susceptible of altering the photophysical outcome of iron(II)-based complexes. The competition between the different factors needs to be fully considered when proceeding to rational molecular design strategy for improving the optical response.

Supplementary Materials: The following are available online, Figures S1-S6 : ${ }^{1} \mathrm{H}$ and ${ }^{13} \mathrm{C}-\mathrm{NMR}$ spectra of L1, L2, C1 and C2, Figure S7: transient spectroscopy, quality of global fit for C1, Figure S8: transient spectroscopy, analysis of vibrational coherence in C1, Figure S9: transient spectroscopy, global fit results for C2, Figure S10: Computational data, Scan of one Fe-N bond distance of $\mathbf{C 1}$ relaxing the $\mathrm{T}_{1}$ state, Tables S1-S15: Xray parameters for C1 and C2, Table S16: transient spectroscopy: fit parameters for C1. CCDC No. are 199232 for C1 and 1982173 for C2.

Author Contributions: M.D. performed the synthesis, ground state characterization of ligands and complexes, and started the initial draft; A.F.-M. and A.M. designed and performed computational work, and wrote the paper; B.M. performed TAS experiments and analysis; A.D. and E.W. performed the crystal growing, the DRX 
experiments and structure elucidation; S.H. designed the TAS experiments, performed them and wrote the paper; P.C.G. coordinated the project, designed the molecular structures and wrote the paper. All authors have read and agreed to the published version of the manuscript.

Funding: This research was funded by the French Agence Nationale de la Recherche (ANR-16-CE07-0013-02) and the Generalitat Valenciana and the European Social Fund (postdoctoral contract APOSTD/2019/149 and project GV/2020/226).

Acknowledgments: The L2CM laboratory is grateful to F. Dupire for mass spectrometry and M. Beley for electrochemistry. The authors thank the $\mathrm{PMD}^{2} \mathrm{X}$ X-ray diffraction facility of the Institut Jean Barriol, Université de Lorraine, for X-ray diffraction measurements, data processing and analysis, and providing of reports for publication: http://crm2.univ-lorraine.fr/lab/fr/services/pmd2x). Calculations have been performed on the local LPCT computing resources and on the Lorraine regional computing center eXplor under the project "Dancing Under the Light", which is gratefully acknowledged. The IPCMS laboratory thanks Edoardo Domenichini for collecting the data on complex $\mathbf{C 2}$.

Conflicts of Interest: The authors declare no conflict of interest.

\section{References}

1. Hagfeldt, A.; Boschloo, G.; Sun, L.; Kloo, L.; Pettersson, H. Dye-Sensitized Solar Cells. Chem. Rev. 2010, 110, 6595-6663. [CrossRef]

2. Vos, J.G.; Kelly, J.M. Ruthenium polypyridyl chemistry; from basic research to applications and back again. Dalton Trans. 2006, 4869-4883. [CrossRef]

3. Pastore, M.; Selloni, A.; Fantacci, S.; De Angelis, F. Electronic and Optical Properties of Dye-Sensitized $\mathrm{TiO}_{2}$ Interfaces. In First Principles Approaches to Spectroscopic Properties of Complex Materials; Di Valentin, C., Botti, S., Cococcioni, M., Eds.; Springer: Berlin/Heidelberg, Germany, 2014; Volume 347, pp. 1-45. ISBN 978-3-642-55067-6.

4. Duchanois, T.; Etienne, T.; Cebrián, C.; Liu, L.; Monari, A.; Beley, M.; Assfeld, X.; Haacke, S.; Gros, P.C. An Iron-Based Photosensitizer with Extended Excited-State Lifetime: Photophysical and Photovoltaic Properties: An Iron-Based Photosensitizer with Extended Excited-State Lifetime. Eur. J. Inorg. Chem. 2015, 2015, 2469-2477. [CrossRef]

5. Marchini, E.; Darari, M.; Lazzarin, L.; Boaretto, R.; Argazzi, R.; Bignozzi, C.A.; Gros, P.C.; Caramori, S. Recombination and regeneration dynamics in FeNHC(II)-sensitized solar cells. Chem. Commun. 2020, 56, 543-546. [CrossRef]

6. Creutz, C.; Chou, M.; Netzel, T.L.; Okumura, M.; Sutin, N. Lifetimes, spectra, and quenching of the excited states of polypyridine complexes of iron(II), ruthenium(II), and osmium(II). J. Am. Chem. Soc. 1980, 102, 1309-1319. [CrossRef]

7. Gawelda, W.; Cannizzo, A.; Pham, V.-T.; van Mourik, F.; Bressler, C.; Chergui, M. Ultrafast Nonadiabatic Dynamics of $\left[\mathrm{Fe}^{\mathrm{II}}(\mathrm{bpy})_{3}\right]^{2+}$ in Solution. J. Am. Chem. Soc. 2007, 129, 8199-8206. [CrossRef] [PubMed]

8. Liu, Y.; Harlang, T.; Canton, S.E.; Chábera, P.; Suárez-Alcántara, K.; Fleckhaus, A.; Vithanage, D.A.; Göransson, E.; Corani, A.; Lomoth, R.; et al. Towards longer-lived metal-to-ligand charge transfer states of iron(II) complexes: An N-heterocyclic carbene approach. Chem. Commun. 2013, 49, 6412-6414. [CrossRef] [PubMed]

9. Liu, L.; Duchanois, T.; Etienne, T.; Monari, A.; Beley, M.; Assfeld, X.; Haacke, S.; Gros, P.C. A new record excited state ${ }^{3}$ MLCT lifetime for metalorganic iron (II) complexes. Phys. Chem. Chem. Phys. 2016, 18, 12550-12556. [CrossRef] [PubMed]

10. Duchanois, T.; Liu, L.; Pastore, M.; Monari, A.; Cebrián, C.; Trolez, Y.; Darari, M.; Magra, K.; Francés-Monerris, A.; Domenichini, E.; et al. NHC-Based Iron Sensitizers for DSSCs. Inorganics 2018, 6, 63. [CrossRef]

11. Francés-Monerris, A.; Magra, K.; Darari, M.; Cebrián, C.; Beley, M.; Domenichini, E.; Haacke, S.; Pastore, M.; Assfeld, X.; Gros, P.C.; et al. Synthesis and Computational Study of a Pyridylcarbene Fe(II) Complex: Unexpected Effects of fac/mer Isomerism in Metal-to-Ligand Triplet Potential Energy Surfaces. Inorg. Chem. 2018, 57, 10431-10441. [CrossRef] [PubMed]

12. Darari, M.; Domenichini, E.; Francés-Monerris, A.; Cebrián, C.; Magra, K.; Beley, M.; Pastore, M.; Monari, A.; Assfeld, X.; Haacke, S.; et al. Iron(II) complexes with diazinyl-NHC ligands: Impact of $\pi$-deficiency of the azine core on photophysical properties. Dalton Trans. 2019, 48, 10915-10926. [CrossRef] [PubMed] 
13. Magra, K.; Domenichini, E.; Francés-Monerris, A.; Cebrián, C.; Beley, M.; Darari, M.; Pastore, M.; Monari, A.; Assfeld, X.; Haacke, S.; et al. Impact of the fac/mer Isomerism on the Excited-State Dynamics of Pyridyl-carbene Fe(II) Complexes. Inorg. Chem. 2019, 58, 5069-5081. [CrossRef] [PubMed]

14. Magra, K.; Darari, M.; Domenichini, E.; Francés-Monerris, A.; Cebrián, C.; Beley, M.; Pastore, M.; Monari, A.; Assfeld, X.; Haacke, S.; et al. Photophysical Investigation of Iron(II) Complexes Bearing Bidentate Annulated Isomeric Pyridine-NHC Ligands. J. Phys. Chem. C 2020, 124, 18379-18389. [CrossRef]

15. Chábera, P.; Kjaer, K.S.; Prakash, O.; Honarfar, A.; Liu, Y.; Fredin, L.A.; Harlang, T.C.B.; Lidin, S.; Uhlig, J.; Sundström, V.; et al. Fe ${ }^{\mathrm{II}}$ Hexa N-Heterocyclic Carbene Complex with a 528 ps Metal-to-Ligand Charge-Transfer Excited-State Lifetime. J. Phys. Chem. Lett. 2018, 9, 459-463. [CrossRef] [PubMed]

16. Braun, J.D.; Lozada, I.B.; Kolodziej, C.; Burda, C.; Newman, K.M.E.; van Lierop, J.; Davis, R.L.; Herbert, D.E. Iron(II) coordination complexes with panchromatic absorption and nanosecond charge-transfer excited state lifetimes. Nat. Chem. 2019, 11, 1144-1150. [CrossRef] [PubMed]

17. Lindh, L.; Chábera, P.; Rosemann, N.W.; Uhlig, J.; Wärnmark, K.; Yartsev, A.; Sundström, V.; Persson, P. Photophysics and Photochemistry of Iron Carbene Complexes for Solar Energy Conversion and Photocatalysis. Catalysts 2020, 10, 315. [CrossRef]

18. Abrahamsson, M.; Jäger, M.; Österman, T.; Eriksson, L.; Persson, P.; Becker, H.-C.; Johansson, O.; Hammarström, L. A 3.0 $\mu$ s Room Temperature Excited State Lifetime of a Bistridentate Ru ${ }^{\mathrm{II}}$-Polypyridine Complex for Rod-like Molecular Arrays. J. Am. Chem. Soc. 2006, 128, 12616-12617. [CrossRef]

19. Hu, Y.-Z.; Wilson, M.H.; Zong, R.; Bonnefous, C.; McMillin, D.R.; Thummel, R.P. A luminescent Pt(II) complex with a terpyridine-like ligand involving a six-membered chelate ring. Dalton Trans. 2005, 354-358. [CrossRef]

20. Vezzu, D.A.K.; Ravindranathan, D.; Garner, A.W.; Bartolotti, L.; Smith, M.E.; Boyle, P.D.; Huo, S. Highly Luminescent Tridentate $\mathrm{N}^{\wedge} \mathrm{C}^{*} \mathrm{~N}$ Platinum(II) Complexes Featured in Fused Five-Six-Membered Metallacycle and Diminishing Concentration Quenching. Inorg. Chem. 2011, 50, 8261-8273. [CrossRef]

21. Mengel, A.K.C.; Förster, C.; Breivogel, A.; Mack, K.; Ochsmann, J.R.; Laquai, F.; Ksenofontov, V.; Heinze, K. A Heteroleptic Push-Pull Substituted Iron(II) Bis(tridentate) Complex with Low-Energy Charge-Transfer States. Chem. Eur. J. 2015, 21, 704-714. [CrossRef]

22. Kjær, K.S.; Kaul, N.; Prakash, O.; Chábera, P.; Rosemann, N.W.; Honarfar, A.; Gordivska, O.; Fredin, L.A.; Bergquist, K.-E.; Häggström, L.; et al. Luminescence and reactivity of a charge-transfer excited iron complex with nanosecond lifetime. Science 2019, 363, 249-253. [CrossRef] [PubMed]

23. Sauvage, J.P.; Collin, J.P.; Chambron, J.C.; Guillerez, S.; Coudret, C.; Balzani, V.; Barigelletti, F.; De Cola, L.; Flamigni, L. Ruthenium(II) and Osmium(II) Bis(terpyridine) Complexes in Covalently-Linked Multicomponent Systems: Synthesis, Electrochemical Behavior, Absorption Spectra, and Photochemical and Photophysical Properties. Chem. Rev. 1994, 94, 993-1019. [CrossRef]

24. Campagna, S.; Puntoriero, F.; Nastasi, F.; Bergamini, G.; Balzani, V. Photochemistry and Photophysics of Coordination Compounds: Ruthenium. In Photochemistry and Photophysics of Coordination Compounds I; Balzani, V., Campagna, S., Eds.; Springer: Berlin/Heidelberg, Germany, 2007; Volume 280, pp. 117-214. ISBN 978-3-540-73346-1.

25. Rillema, D.P.; Jones, D.S. Structure of tris(2,2'-bipyridyl)ruthenium(II) hexafluorophosphate, $\left[\mathrm{Ru}(\text { bipy })_{3}\right]\left[\mathrm{PF}_{6}\right]_{2} ; \mathrm{X}$-ray crystallographic determination. J. Chem. Soc. Chem. Commun. 1979, 849-851. [CrossRef]

26. Medlycott, E.A.; Hanan, G.S. Designing tridentate ligands for ruthenium(II) complexes with prolonged room temperature luminescence lifetimes. Chem. Soc. Rev. 2005, 34, 133-142. [CrossRef]

27. Dinda, J.; Liatard, S.; Chauvin, J.; Jouvenot, D.; Loiseau, F. Electronic and geometrical manipulation of the excited state of bis-terdentate homo- and heteroleptic ruthenium complexes. Dalton Trans. 2011, 40, 3683-3688. [CrossRef]

28. Otto, S.; Grabolle, M.; Förster, C.; Kreitner, C.; Resch-Genger, U.; Heinze, K. [Cr(ddpd) $]^{3+}$ : A Molecular, Water-Soluble, Highly NIR-Emissive Ruby Analogue. Angew. Chem. Int. Ed. 2015, 54, 11572-11576. [CrossRef]

29. Otto, S.; Scholz, N.; Behnke, T.; Resch-Genger, U.; Heinze, K. Thermo-Chromium: A Contactless Optical Molecular Thermometer. Chem. Eur. J. 2017, 23, 12131-12135. [CrossRef]

30. Jamula, L.L.; Brown, A.M.; Guo, D.; McCusker, J.K. Synthesis and Characterization of a High-Symmetry Ferrous Polypyridyl Complex: Approaching the ${ }^{5} \mathrm{~T}_{2} /{ }^{3} \mathrm{~T}_{1}$ Crossing Point for Fe ${ }^{\mathrm{II}}$. Inorg. Chem. 2014, 53, $15-17$. [CrossRef] 
31. Gründemann, S.; Albrecht, M.; Loch, J.A.; Faller, J.W.; Crabtree, R.H. Tridentate Carbene CCC and CNC Pincer Palladium(II) Complexes: Structure, Fluxionality, and Catalytic Activity. Organometallics 2001, 20, 5485-5488. [CrossRef]

32. Slavov, C.; Hartmann, H.; Wachtveitl, J. Implementation and Evaluation of Data Analysis Strategies for Time-Resolved Optical Spectroscopy. Anal. Chem. 2015, 87, 2328-2336. [CrossRef]

33. Snellenburg, J.J.; Laptenok, S.P.; Seger, R.; Mullen, K.M.; Stokkum, I.H.M. van Glotaran: A Java -Based Graphical User Interface for the R Package TIMP. J. Stat. Softw. 2012, 49. [CrossRef]

34. Tatsuno, H.; Kjær, K.S.; Kunnus, K.; Harlang, T.C.B.; Timm, C.; Guo, M.; Chàbera, P.; Fredin, L.A.; Hartsock, R.W.; Reinhard, M.E.; et al. Hot Branching Dynamics in a Light-Harvesting Iron Carbene Complex Revealed by Ultrafast X-ray Emission Spectroscopy. Angew. Chem. Int. Ed. 2020, 59, 364-372. [CrossRef] [PubMed]

35. Kunnus, K.; Vacher, M.; Harlang, T.C.B.; Kjær, K.S.; Haldrup, K.; Biasin, E.; van Driel, T.B.; Pápai, M.; Chabera, P.; Liu, Y.; et al. Vibrational wavepacket dynamics in Fe carbene photosensitizer determined with femtosecond X-ray emission and scattering. Nat. Commun. 2020, 11, 634. [CrossRef] [PubMed]

36. Cannizzo, A.; Milne, C.J.; Consani, C.; Gawelda, W.; Bressler, C.; van Mourik, F.; Chergui, M. Light-induced spin crossover in $\mathrm{Fe}(\mathrm{II})$-based complexes: The full photocycle unraveled by ultrafast optical and X-ray spectroscopies. Coord. Chem. Rev. 2010, 254, 2677-2686. [CrossRef]

37. Consani, C.; Prémont-Schwarz, M.; ElNahhas, A.; Bressler, C.; van Mourik, F.; Cannizzo, A.; Chergui, M. Vibrational Coherences and Relaxation in the High-Spin State of Aqueous $\left[\mathrm{Fe}^{\mathrm{II}}(\mathrm{bpy})_{3}\right]^{2+}$. Angew. Chem. Int. Ed. 2009, 48, 7184-7187. [CrossRef]

38. Wolf, M.M.N.; Groß, R.; Schumann, C.; Wolny, J.A.; Schünemann, V.; Døssing, A.; Paulsen, H.; McGarvey, J.J.; Diller, R. Sub-picosecond time resolved infrared spectroscopy of high-spin state formation in Fe(II) spin crossover complexes. Phys. Chem. Chem. Phys. 2008, 10, 4264-4273. [CrossRef]

39. Francés-Monerris, A.; Gros, P.C.; Assfeld, X.; Monari, A.; Pastore, M. Toward Luminescent Iron Complexes: Unravelling the Photophysics by Computing Potential Energy Surfaces. ChemPhotoChem 2019, 3, 666-683. [CrossRef]

40. Dolomanov, O.V.; Bourhis, L.J.; Gildea, R.J.; Howard, J.A.K.; Puschmann, H. OLEX2: A complete structure solution, refinement and analysis program. J. Appl. Crystallogr. 2009, 42, 339-341. [CrossRef]

41. Sheldrick, G.M. A short history of SHELX. Acta Crystallogr. A 2008, 64, 112-122. [CrossRef]

42. Francés-Monerris, A.; Gros, P.C.; Pastore, M.; Assfeld, X.; Monari, A. Photophysical properties of bichromophoric Fe(II) complexes bearing an aromatic electron acceptor. Theor. Chem. Acc. 2019, 138, 86. [CrossRef]

43. Frisch, M.J.; Trucks, G.W.; Schlegel, H.B.; Scuseria, G.E.; Robb, M.A.; Cheeseman, J.R.; Scalmani, G.; Barone, V.; Petersson, G.A.; Nakatsuji, H.; et al. Gaussian 16, Revision C.01. Gaussian, Inc.: Wallingford, CT, USA, 2016. Available online: https://gaussian.com/citation/ (accessed on 30 October 2020).

44. Boese, A.D.; Handy, N.C. A new parametrization of exchange-correlation generalized gradient approximation functionals. J. Chem. Phys. 2001, 114, 5497-5503. [CrossRef]

45. Hirata, S.; Head-Gordon, M. Time-dependent density functional theory within the Tamm-Dancoff approximation. Chem. Phys. Lett. 1999, 314, 291-299. [CrossRef]

46. Grimme, S.; Antony, J.; Ehrlich, S.; Krieg, H. A consistent and accurate ab initio parametrization of density functional dispersion correction (DFT-D) for the 94 elements H-Pu. J. Chem. Phys. 2010, 132, 154104. [CrossRef] [PubMed]

47. Martin, R.L. Natural transition orbitals. J. Chem. Phys. 2003, 118, 4775-4777. [CrossRef]

48. Etienne, T.; Assfeld, X.; Monari, A. Toward a Quantitative Assessment of Electronic Transitions' Charge-Transfer Character. J. Chem. Theory Comput. 2014, 10, 3896-3905. [CrossRef]

49. Etienne, T.; Assfeld, X.; Monari, A. New Insight into the Topology of Excited States through Detachment/Attachment Density Matrices-Based Centroids of Charge. J. Chem. Theory Comput. 2014, 10, 3906-3914. [CrossRef]

50. Pápai, M.; Vankó, G.; Rozgonyi, T.; Penfold, T.J. High-Efficiency Iron Photosensitizer Explained with Quantum Wavepacket Dynamics. J. Phys. Chem. Lett. 2016, 7, 2009-2014. [CrossRef]

51. Paulus, B.C.; Adelman, S.L.; Jamula, L.L.; McCusker, J.K. Leveraging excited-state coherence for synthetic control of ultrafast dynamics. Nature 2020, 582, 214-218. [CrossRef] 
52. Bauer, M.; Steube, J.; Päpcke, A.; Bokareva, O.; Reuter, T.; Demeshko, S.; Schoch, R.; Hohloch, S.; Meyer, F.; Heinze, K.; et al. Janus-type dual emission of a Cyclometalated Iron(III) complex. 2020; in review.

53. Steube, J.; Burkhardt, L.; Päpcke, A.; Moll, J.; Zimmer, P.; Schoch, R.; Wölper, C.; Heinze, K.; Lochbrunner, S.; Bauer, M. Excited-State Kinetics of an Air-Stable Cyclometalated Iron(II) Complex. Chem. Eur. J. 2019, 25, 11826-11830. [CrossRef]

54. Tang, Z.; Chang, X.-Y.; Wan, Q.; Wang, J.; Ma, C.; Law, K.-C.; Liu, Y.; Che, C.-M. Bis(tridentate) Iron(II) Complexes with a Cyclometalating Unit: Photophysical Property Enhancement with Combinatorial Strong Ligand Field Effect. Organometallics 2020, 39, 2791-2802. [CrossRef]

Sample Availability: Samples of the compounds are not available from the authors.

Publisher's Note: MDPI stays neutral with regard to jurisdictional claims in published maps and institutional affiliations.

(C) 2020 by the authors. Licensee MDPI, Basel, Switzerland. This article is an open access article distributed under the terms and conditions of the Creative Commons Attribution (CC BY) license (http://creativecommons.org/licenses/by/4.0/). 